\title{
Maximum heat ratio: bi-directional method for fast and slow sap flow measurements
}

\author{
Jose Gutierrez Lopez (D) Thomas Pypker • \\ Julian Licata $\cdot$ Stephen S. O. Burgess • \\ Heidi Asbjornsen
}

Received: 23 January 2021 / Accepted: 23 June 2021 / Published online: 21 September 2021

(C) The Author(s) 2021, corrected publication 2022

\begin{abstract}
Background As sap flow research expands, new challenges such as fast sap flows or flows co-occurring with freeze/thaw cycles appear, which are not easily addressed with existing methods. In order to address these new challenges, sap flow methods capable of measuring bidirectional, high and slow sap flux densities $\left(\boldsymbol{F}_{\boldsymbol{d}}, \mathrm{cm}^{3} \mathrm{~cm}^{-2} \mathrm{~h}^{-1}\right)$, thermal properties and stem water content with minimum sensitivity to stem temperature are required.

Purpose In this study we assessed the performance of a new low-power ratio-based algorithm, the maximum
\end{abstract}

Responsible Editor: Rafael S. Oliveira.

J. G. Lopez $(\bowtie) \cdot H$. Asbjornsen

Earth Systems Research Center, University of New

Hampshire, Durham, NH 03824, USA

e-mail: gutloja@gmail.com; jose.lopez@slu.se

J. G. Lopez

Department of Forest Ecology and Management, Swedish

University of Agricultural Sciences, 90736 Umeå, Sweden

T. Pypker

Department of Natural Resource Sciences, Thompson

Rivers University, Kamloops, BC V2C0C8, Canada

J. Licata

Institutional Research and Effectiveness, Bemidji State

University, Bemidji, MN 56601, USA

S. S. O. Burgess

School of Biological Sciences M090, University

of Western Australia, WA 6009 Perth, Australia heat ratio (MHR) method, and compare it with the widely known heat ratio (HR) method using a cut-tree study to test it under high flows using Eucalyptus grandis trees, and a freeze/thaw experiment using Acer saccharum trunks to test its response to fast changing stem temperatures that result in freeze/thaw cycles.

Results Our results indicate that MHR and HR had a strong $\left(\mathrm{R}^{2}=0.90\right)$ linear relationship within a $F_{d}$ range of $0-45 \mathrm{~cm}^{3} \mathrm{~cm}^{-2} \mathrm{~h}^{-1}$. Using the MHR algorithm, we were able to estimate wood thermal properties and water content, while extending the measuring range of HR to approximately $0-130\left(\mathrm{~cm}^{3} \mathrm{~cm}^{-2} \mathrm{~h}^{-1}\right)$. In our freeze/thaw experiment, the main discrepancy between MHR and HR was observed during freezing, where HR had consistently lower $F_{d}$ (up to 10 $\mathrm{cm}^{3} \mathrm{~cm}^{-2} \mathrm{~h}^{-1}$ ), with respect to MHR. However, both algorithms identified similar zero flows.

Conclusion Consequently, MHR can be an easy-toimplement alternative algorithm/method capable of handling extreme climatic conditions, which can also run simultaneously with HR.

Keywords Maximum heat ratio $\cdot$ Thermal diffusivity $\cdot$ Volumetric water content $\cdot$ Freeze/thaw cycles $\cdot$ Volumetric heat capacity

\section{Introduction}

As various sap flow methods move into extreme environments, new measuring challenges such as very fast 
flows, or flows accompanied with fast stem temperature changes that result in freeze/thaw cycles appear. Coincidentally, these challenges are common in remote locations, where low-power sap flow methods, capable of measuring fast, slow, zero, and reverse flows are ideal. In general terms, there are two categories of commonly used thermometric sap flow sensors: heat dissipation (HD) (Clearwater et al. 1999; Granier 1985) and heat pulse (HP) methods (Cohen et al. 1981; Marshall 1958; Swanson 1962), which refers to the way the heat is released into the conductive tissue (i.e., sapwood) to monitor sap flow, and also defines their power consumption (pulse-based methods often having the least power requirements). Two of the common variations within the HP methods include the Tmax (Cohen et al. 1981) and the heat ratio (HR) (Burgess et al. 2001). Both the Tmax and HR methods are improvements from previous methods, and due to their working principles and the data they require, each exhibit optimal performance and accuracy within different ranges of sap flux densities $\left(\boldsymbol{F}_{\boldsymbol{d}}, \mathrm{cm}^{3} \mathrm{~cm}^{-2} \mathrm{~h}^{-1}\right)$ with high accuracy; Tmax for fast, and HR for slow, zero and reverse $F_{d}$. Of these two, only the HR method is capable of measuring positive (towards the canopy) and negative (towards the roots) flows, and because of its low-power requirements, it is ideal for extreme environments (e.g., plantations of fast-growing species, sites at high latitudes) where maintenance is difficult due to site accessibility. However, because of the working principle of the HR method, which requires a 60 -s waiting period after the heat pulse to trace sap flow (Burgess et al. 2001), this method tends to fail at high flows since under these conditions the measurement period does not effectively capture the effects of heat convection on the heat pulse released into the sapwood. The relatively recently developed dual method approach (DMA, Forster 2019, 2020), addresses this issue by estimating $F_{d}$ with both HR and Tmax methods, and outputs $F_{d}$ from HR if conduction is less than convection, and $F_{d}$ from Tmax if conduction exceeds convection. Table 1 shows the entire nomenclature used in this study.

Although HR, Tmax or DMA are referred to as separate methods, in essence they are simply alternative data processing algorithms used to infer heat pulse velocity $\left(V_{h}, \mathrm{~cm} \mathrm{~h}^{-1}\right)$ and $F_{d}$ from temperature measurements following the heat conduction-convection equation (Carslaw and Jaeger 1947; Marshall 1958; Vandegehuchte and Steppe 2012b):

$$
\rho c \frac{\partial T}{\partial t}=\left\lceil\frac{\partial}{\partial x}\left(K_{a x} \frac{\partial T}{\partial x}\right)+\frac{\partial}{\partial y}\left(K_{t g} \frac{\partial T}{\partial y}\right)+\frac{\partial}{\partial z}\left(K_{r d} \frac{\partial T}{\partial z}\right) 1-\rho c V_{c} \frac{\partial T}{\partial t}+P\right.
$$

which defines the way a pulse of heat propagates inside an anisotropic medium, which expressed in terms of temperature changes at a positive (up $=\Delta \mathrm{T}_{\mathrm{u}},{ }^{\circ} \mathrm{C}$ ) or negative (down $=\Delta \mathrm{T}_{\mathrm{d}},{ }^{\circ} \mathrm{C}$ ) distance from the heater source perpendicular to the sap flow (Fig. 1-a,b), yields:

$\Delta T_{u}=\frac{q}{4 \pi K t} \operatorname{Ei}\left(\frac{\rho c}{4 K} \frac{\left(x_{u}+V_{h} t\right)^{2}}{t}\right)$

$\Delta T_{u}=\frac{q}{4 \pi K t} \operatorname{Ei}\left(\frac{\rho c}{4 K} \frac{\left(x_{u}-V_{h} t\right)^{2}}{t}\right)$

Also expressed assuming an isotropic medium (i.e., equal $\mathrm{K}$ in the axial and tangential directions):

$\Delta T=\frac{q}{4 \pi K t} \operatorname{Ei}\left(\frac{\rho c}{4 t} \frac{\left(x-V_{h} t\right)^{2}}{K}\right)$

where $\mathrm{q}$ is the power released by the heater per unit length $\left(\mathrm{W} \mathrm{m}^{-1}\right), \rho \mathrm{c}$ is the volumetric heat capacity of the green wood $\left(\mathrm{J} \mathrm{m}^{-3} \mathrm{~K}^{-1}\right), \mathrm{K}$ the thermal conductivity ( $\mathrm{W} \mathrm{m}^{-1} \mathrm{~K}^{-1}$ ), $V_{h}$ the heat pulse velocity, differentiated to zero and Ei the exponential integral. Due to previous data storage and data processing limitations (e.g., the first computing algorithm for Ei appeared a decade later) (Cody and Thacher 1968), attempts have been made to simplify Eq. 2 or to select specific points within the $\Delta \mathrm{T}$ curve (Fig. 1-a) that allow to estimate $V_{h}$ and $F_{d}$ with minimal computing power. One of these attempts was the Tmax method, which is based on the property of the $\Delta \mathrm{T}$ curve, that when the maximum $\Delta \mathrm{T}\left(\mathrm{t}_{\mathrm{m}}\right)$ occurs, its slope is also zero. At this particular point, it is possible to ignore the first term of Eq. 2, and only the thermal diffusivity ( $\mathrm{D}, \mathrm{m}^{-2} \mathrm{~s}^{-1}$ ) and the distance to the heater source $(x, m)$ become relevant to estimate the heat pulse velocity using (Cohen et al. 1981):

$V_{h}=\sqrt{\frac{x^{2}-4 D t_{m}}{t_{m}}}$

which additionally, under conditions of zero convective heat transport, $\mathrm{D}$ can be estimated using:

$D=\frac{x^{2}}{4 t_{m}}$

Or with: 
Table 1 Nomenclature and their use

\begin{tabular}{|c|c|c|}
\hline Symbol & Units & Explanation \& use \\
\hline$\Delta \mathrm{T}$ & ${ }^{\circ} \mathrm{C} / \mathrm{K}$ & $\begin{array}{l}\text { Changes in temperature, usually after the heat pulse. Note that due to the linearity between }{ }^{\circ} \mathrm{C} \text { and } \\
\text { Kelvin, any } \Delta \mathrm{T} \text { can be expressed in }{ }^{\circ} \mathrm{C} \text { or Kelvin }\end{array}$ \\
\hline$t_{m}$ & seconds & Time at which maximum $\Delta$ T occurs. In Eq. 6 it can be entered in hours \\
\hline$\Delta \mathrm{T}_{\mathrm{u}}$ & ${ }^{\circ} \mathrm{C} / \mathrm{K}$ & $\Delta \mathrm{T}$ at a positive (up) position from the heater \\
\hline$\Delta \mathrm{T}_{\mathrm{d}}$ & ${ }^{\circ} \mathrm{C} / \mathrm{K}$ & $\Delta \mathrm{T}$ at a negative (down) position from the heater \\
\hline $\mathrm{T}_{\mathrm{u}}$ & ${ }^{\circ} \mathrm{C}$ & $T$ at a positive (up) position from the heater \\
\hline $\mathrm{T}_{\mathrm{d}}$ & ${ }^{\circ} \mathrm{C}$ & $T$ at a negative (down) position from the heater \\
\hline q & $\mathrm{W} \mathrm{m}^{-1}$ & Power released by the heater by unit length \\
\hline $\mathrm{P}$ & $\mathrm{W} \mathrm{m}^{-3}$ & External heat input \\
\hline$\rho c$ & $\mathrm{~J} \mathrm{~m}^{-3} \mathrm{~K}^{-1}$ & Volumetric heat capacity of sapwood \\
\hline $\mathrm{K}$ & $\mathrm{W} \mathrm{m} \mathrm{m}^{-1} \mathrm{~K}^{-1}$ & Thermal conductivity of sapwood \\
\hline $\mathrm{K}_{\mathrm{ax}}$ & $\mathrm{W} \mathrm{m} \mathrm{m}^{-1} \mathrm{~K}^{-1}$ & Axial K \\
\hline $\mathrm{K}_{\mathrm{tg}}$ & $\mathrm{W} \mathrm{m} \mathrm{m}^{-1} \mathrm{~K}^{-1}$ & Tangential K \\
\hline $\mathrm{K}_{\mathrm{rd}}$ & $\mathrm{W} \mathrm{m} \mathrm{m}^{-1} \mathrm{~K}^{-1}$ & Radial K \\
\hline $\mathrm{t}$ & seconds & Time before or after the heat pulse \\
\hline $\mathrm{x}$ & meters & Distance from the heater to the measurement point. Note that $\mathrm{x}$ can be entered in $\mathrm{cm}$ in Eq. 5 and Eq. 6 \\
\hline $\mathrm{x}_{\mathrm{u}}$ & meters & $\mathrm{x}$ at a positive (up) position from the heater \\
\hline $\mathrm{x}_{\mathrm{d}}$ & meters & $\mathrm{x}$ at a negative (down) position from the heater \\
\hline $\mathrm{V}_{\mathrm{h}}$ & $\mathrm{cm} \mathrm{h}^{-1}$ & Heat pulse speed (velocity). Note than in Eq. 2, Eq. 3 and Eq. $4, V_{h}$ is in $\mathrm{m} \mathrm{s}^{-1}$ \\
\hline $\mathrm{V}_{\mathrm{c}}$ & $\mathrm{cm} \mathrm{h}^{-1}$ & $\mathrm{~V}_{\mathrm{h}}$ corrected for wounding \\
\hline $\mathrm{V}_{\mathrm{s}}$ & $\mathrm{cm} \mathrm{h}^{-1}$ & Sap velocity \\
\hline $\mathrm{Ei}$ & & Exponential integral \\
\hline $\mathrm{D}$ & $\mathrm{m}^{2} \mathrm{~s}^{-1}$ & Thermal diffusivity of sapwood \\
\hline $\mathrm{V}$ & Volts & Voltage applied to the heaters \\
\hline $\mathrm{R}$ & $\Omega$ & Total resistance of the heater \\
\hline $\mathrm{R}_{\mathrm{L}}$ & $\Omega \mathrm{m}^{-1}$ & $\mathrm{R}$ expressed in length \\
\hline$\rho_{\mathrm{w}}$ & $\mathrm{kg} \mathrm{m}^{-3}$ & Bulk density of the sapwood \\
\hline$\rho_{\mathrm{s}}$ & $\mathrm{kg} \mathrm{m}^{-3}$ & Bulk density of sap, assumed to be similar to density of water \\
\hline$\theta_{v}$ & $\mathrm{~m}^{3} \mathrm{~m}^{-3}$ & Volumetric water content \\
\hline$c_{w}$ & $\mathrm{~J} \mathrm{~kg}^{-1} \mathrm{~K}^{-1}$ & Specific heat capacity of sapwood \\
\hline $\mathrm{c}_{\mathrm{s}}$ & $\mathrm{J} \mathrm{kg}^{-1} \mathrm{~K}^{-1}$ & Specific heat capacity of sap, assumed similar to water \\
\hline$F_{d}$ & $\mathrm{~cm}^{3} \mathrm{~cm}^{-2} \mathrm{~h}^{-1}$ & Sap flux density \\
\hline$D_{s}$ & $0-1$ & Normalized sapwood depth \\
\hline$A_{s}$ & $\mathrm{~cm}^{2}$ & Sapwood area \\
\hline$Q$ & Liters $\mathrm{h}^{-1}$ & Sap flow \\
\hline$G W U$ & Liters $\mathrm{h}^{-1}$ & Gravimetric water use \\
\hline
\end{tabular}

$D=\frac{K}{\rho c}$

When the $V_{h}$ is slow, finding $\mathrm{t}_{\mathrm{m}}$ in the $\Delta \mathrm{T}$ curve is challenging and consequently Eq. 5 and Eq. 6 over or underestimate $V_{h}$ and $\mathrm{D}$, respectively. It was also proposed that the maximum $T$ in a $T_{u}-T_{d}$ (Fig. 1-c) curve also satisfied Eq. 5 (Cohen et al.
1981), but this approach is not sensitive to slow flows. An additional alternative to increase sensibility to slow and zero flows, while minimizing computing requirements, was to collect measurements above and below the heater (Fig. 1-a,b), to divide their respective equations (e.g., Eq. 2 and Eq. 3) (Burgess et al. 2001; Marshall 1958), which 

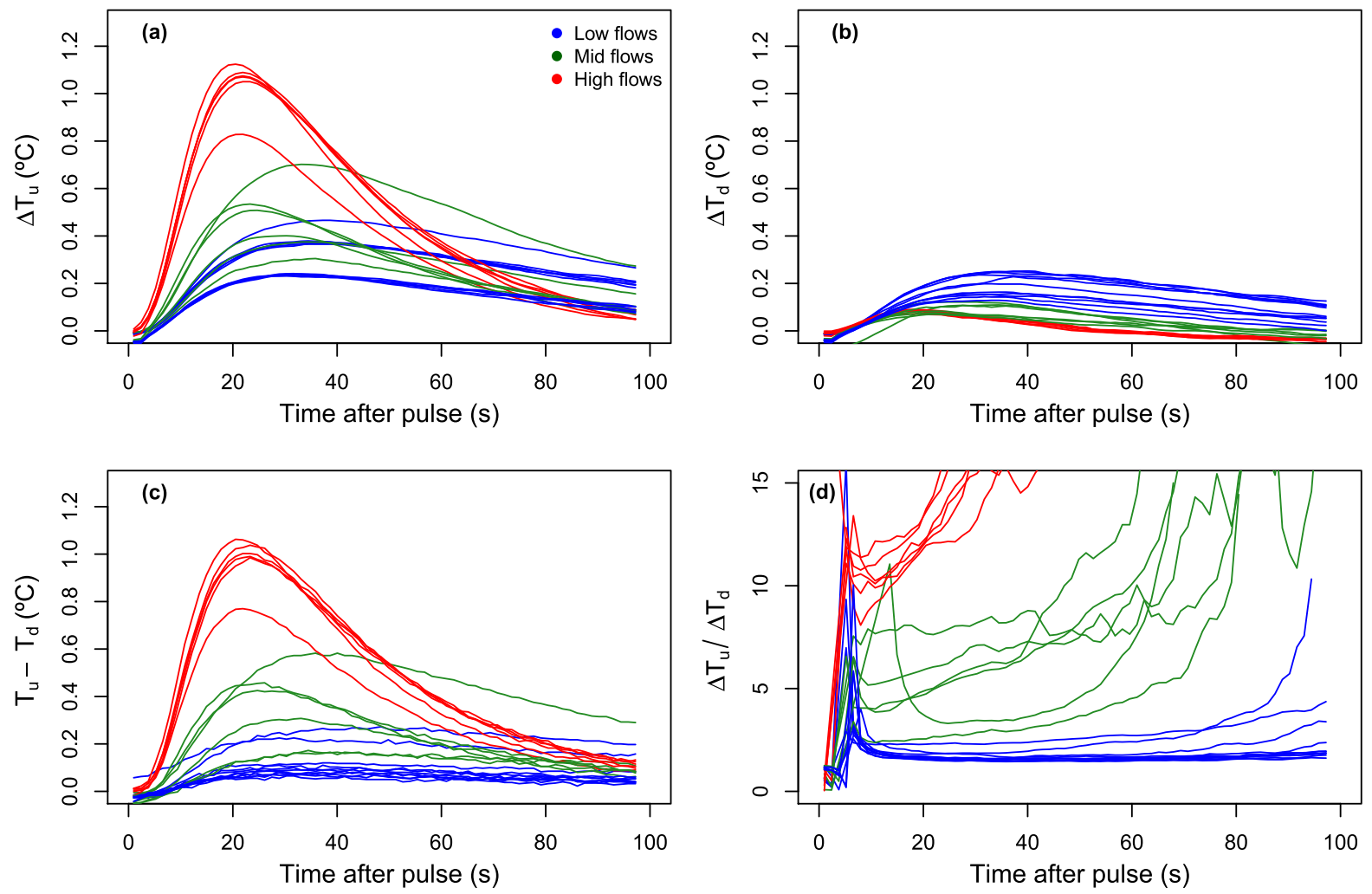

Fig. 1 Measurements use to estimate heat pulse velocity $\left(V_{h}, \mathrm{~cm} \mathrm{~h}^{-1}\right)$ following a short $(<3 \mathrm{~s})$ heat pulse. $(\mathbf{a}, \mathbf{b})$ Temperature increments in a probe at a positive $\left(\Delta \mathrm{T}_{\mathrm{u}}\right)$ and negative $\left(\Delta \mathrm{T}_{\mathrm{u}}\right)$ distance from a heater source. (c) Differential tem-

eliminates the first component of the equations, resulting in:

$\frac{\Delta T_{u}}{\Delta T_{d}}=E i\left\lceil\frac{\left(x_{u}+V_{h} t\right)^{2}-\left(x_{d}-V_{h} t\right)^{2}}{4 D t}\right\rceil$

which solving for $V_{h}$ yields:

$V_{h}=\frac{2 D}{x_{u}+x_{d}} \ln \left(\frac{\Delta T_{u}}{\Delta T_{d}}\right)+\frac{x_{u}-x_{d}}{2 t}$

Were if $\mathrm{x}_{\mathrm{u}}$ and $\mathrm{x}_{\mathrm{d}}$ are equidistant the last term can be ignored resulting in:

$V_{h}=\frac{D}{x} \ln \left(\frac{\Delta T_{u}}{\Delta T_{d}}\right) 3600$

where D can be estimated using Eq. 6 or Eq. 7. The versatility of this equation is that it is not necessary to know the specific amount of heat released

perature between $T_{u}$ and $T_{d}$ from the heater source. (d) Ratio between $\Delta \mathrm{T}_{\mathrm{u}}$ and $\Delta \mathrm{T}_{\mathrm{u}}$. All data has been color-coded according to estimated $F_{d}$ range: blue $<20$, green $20-60$, red $>60$ $\mathrm{cm}^{3} \mathrm{~cm}^{-2} \mathrm{~h}^{-1}$

by the heater. Additionally, this alternative makes it very easy to estimate zero flow. But as mentioned before, one consequence of this algorithm is that the $\Delta \mathrm{T}_{\mathrm{u}} / \Delta \mathrm{T}_{\mathrm{d}}$ curve becomes unstable during fast flows, primarily because $\Delta \mathrm{T}_{\mathrm{d}}$ approaches zero. However, independently of the algorithm used to estimate $V_{h}$, any sensor capable of generating both $\Delta \mathrm{T}_{\mathrm{u}}$ and $\Delta \mathrm{T}_{\mathrm{d}}$ curves, can be used to estimate: $F_{d}$ with both HR and Tmax methods, thermal properties such as $\mathrm{K}$ and $\rho \mathrm{c}$, and volumetric water content (see details below for how thermal properties such as $\rho \mathrm{c}$, can be used to estimate volumetric water content), provided the right data are collected. The challenge is to select the point or points in the $\Delta \mathrm{T}_{\mathrm{u}} / \Delta \mathrm{T}_{\mathrm{d}}$ curve that satisfy Eq. 9 and Eq. 10. More specifically, the challenge is to identify the $\Delta \mathrm{T}_{\mathrm{u}} / \Delta \mathrm{T}_{\mathrm{d}}$ data points, that maintain a linearity with $F_{d}$ as $V_{h}$ increases. Marshall (1958) provided the theoretical background to show that overall $\Delta \mathrm{T}_{\mathrm{u}}$ l $\Delta \mathrm{T}_{\mathrm{d}}$ satisfies Eq. 10, but there were nearly no further 
developments (see: Hogg and Hurdle 1997). Burgess et al (2001) selected the mean from 60-100 s after the pulse within the $\Delta \mathrm{T}_{\mathrm{u}} / \Delta \mathrm{T}_{\mathrm{d}}$ curve (mainly because it is fairly linear within this range) and proposed the now widespread method/algorithm known as the heat ratio method (HR) that has shown high precision within $F_{d}$ from -45 to $+45\left(\mathrm{~cm}^{3} \mathrm{~cm}^{-2} \mathrm{~h}^{-1}\right)$.

Consequently, there is no universally-accepted sap flow method, most are prone to technical complications, and rely on calibrations to improve measurement accuracy (Flo et al. 2019; Swanson 1994; Vandegehuchte and Steppe 2013). For example, HD methods (e.g., Granier 1985) can result in significant underestimations of $F_{d}$ (up to 60\%) (Cabibel and Do 1991; Flo et al. 2019; Lu and Chacko 1998; Lundblad et al. 2001; Steppe et al. 2010; Sun et al. 2012). But after calibration, HD performs equally, or better than HP methods, especially at fast $F_{d}$ ranges (Gutierrez Lopez et al. 2018; Gutiérrez Lopez et al. 2018). Consequently, the selection of sap flow methods is often based on method complexity, cost, power use and associated stand-alone time (i.e. the time $\mathrm{n}$ sensors can be powered out of a rechargeable battery), and more importantly, the expected ranges of $F_{d}$ to be measured. Method complexity in particular, has helped HD methods (Clearwater et al. 1999; Granier 1985) become more popular, compared to heat pulse methods which require more complex programing for data collection and processing. However, with the widespread availability of large-memory storage devices, storing entire $\Delta \mathrm{T}$ curves to run any algorithm on Eq. 4 to estimate simultaneously $V_{h}, F_{d}$, wood thermal properties, and volumetric water content is currently more viable.

Sap flow research has become a fundamental part of studies seeking to understand responses of individual plants, whole stands and ecosystems, to abiotic and biotic drivers (Alvarado-Barrientos et al. 2013; Eller et al. 2015; Kagawa et al. 2009; Kukowski et al. 2013; Lundblad and Lindroth 2002; Meinzer et al. 2004; Steppe et al. 2006; Vergeynst et al. 2014; Zalesny et al. 2006). In physiological studies, sap flow measurements can help identify the underlying mechanisms that explain changes in water movement along the soil-plant-atmosphere continuum at the individual plant scale. In ecological studies, sap flow measurements help examine the responses of ecosystem processes and functions related to water use and cycling to environmental change (e.g., disturbance, drought, nutrient amendments, etc.). In both ecological and physiological studies, HP methods capable of measuring slow, zero and reverse flows (i.e., HR method) receive overall less attention, in part because most studies focus primarily on transpiration-induced sap flow, where the vast majority of the flow is positive. Methods capable of measuring bidirectional flows are then ideal in studies interested in hydraulic redistribution in roots (Burgess et al. 2000), foliar water uptake (Schreel and Steppe 2019), studies focused on nontranspiration sap flow, or studies where tree transpiration occurs when stem temperature crosses the freezing point of sap, where both positive and negative flows need to be accounted for (Cienciala et al. 1999; Gutierrez Lopez et al. 2021; Hasper et al. 2016; Kozii et al. 2020; Lagergren and Lindroth 2002). In environmental conditions that result in fast bidirectional flows, the equidistant placement of temperaturemonitoring probes around the heater source, HR and other bidirectional methods offer a greater advantage at identifying periods of time when sap flow is zero or reverse. In traditional unidirectional HD methods (i.e. Clearwater et al. 1999; Granier 1985) an equilibrum period overnight is required to determine zero flow, and since this is often hard to achieve, this has become the subject of extensive research (Bush et al. 2010; Do and Rocheteau 2002; Forster 2017; Oishi et al. 2016; Peters et al. 2018; Rabbel et al. 2016; Regalado and Ritter 2007; Vergeynst et al. 2014), often involving as much computing power as HP methods.

Alternatives to HD and HP methods (e.g., Tmax, HR) exist, such as the Sapflow + or the DMA, which can account for changes in volumetric water content in the sapwood, albeit no details are available on how the later estimates stem water content (Forster 2019, 2020). However, at this time their application is limited. The Sapflow + method (Vandegehuchte and Steppe 2012b) uses four probes to estimate $F_{d}$. While it is advantageous, because it estimates sapwood water content, and accounts for anisotropic thermal properties, for ecological studies, it is important to consider the possible limitations created by increasing the number of probes per sensor (which might limit sample size) and increase wounding effects, as shown in similar methods (Burgess et al. 2001). The DMA is a recently published algorithm that requires the estimation of $F_{d}$ with both Tmax and HR methods, and estimate the ratio between heat conduction 
and convection to decide which $F_{d}$ is reported. These additional data processing requirements might discourage new users. DMA is arguably a good alternative to extend the measuring range of $\mathrm{HR}$, however the effects of switching from a ratio to a non-ratio method remains to be more widely tested, particularly given each method will have its own relationship to the theories and practice of wound correction and adjustment for wood thermal properties (see previous discussion on how $V_{h}$ is estimated with Tmax and HR methods using Eq. 5 and Eq. 10, respectively). Another alternative is the compensation heat pulse (CHP) method, which has been validated under field and laboratory conditions (Fernandez et al. 2006; Poblete-Echeverria et al. 2012; Vandegehuchte et al. 2015), however, this method is also known to perform poorly at slow $F_{d}$ ranges (Becker 1998; Burgess et al. 2000).

Consequently, increasing the measuring range of the already validated HR method (initially estimated to be from -55 to $+55 \mathrm{~cm}^{3} \mathrm{~cm}^{-2} \mathrm{~h}^{-1}$, when $\mathrm{D}$ is approximately $2 \times 10^{-7} \mathrm{~m}^{2} \mathrm{~s}^{-1}$ ) is then of great interest for ecological and physiological studies, which could additionally eliminate the need to use various methods to make comparisons while providing the advantages of a low-powered method. To our knowledge, only one study (Vandegehuchte et al. 2015) has experimented with the data analysis algorithm of HR and studied how changes in diel stem temperature affect $F_{d}$ measurements, but no analysis were performed below the freezing point of sap. According to their results, estimating the ratio at different time intervals within the $\Delta \mathrm{T}_{\mathrm{u}} / \Delta \mathrm{T}_{\mathrm{d}}$ curve after the heat pulse (compared to the standard 60-100 s after the pulse), increases the measuring range of $F_{d}$, but we are not aware if validations of any additional algorithms to extend the measuring range of HR have been published.

In this study, we tested and validated a new data analysis algorithm that is based on a similar data collection and processing routine to the HR method, which we call the maximum heat ratio (MHR) algorithm. The MHR algorithm is an alternative to extend the measuring range of HR, that we show is similar to $F_{d}$ estimates derived from the HR method (within its measuring range), and also matches high flows estimated by Tmax methods (known for their reliability at high flows). Additionally, we show the process to estimate thermal properties and volumetric water content when $\Delta \mathrm{T}_{\mathrm{u}}$ and $\Delta \mathrm{T}_{\mathrm{d}}$ curves are available. We conducted a validation in two experiments, (a) a cut-tree experiment using eight one-year-old Eucalyptus grandis Hill ex Maiden trees and (b) a freeze/ thaw experiment using two freshly harvested Acer saccharum Marshall trunks. The overarching goal of this study was to test and validate the new MHR algorithm, establish its measurement range, and test its performance on high flows and extreme environmental conditions, especially when the stems often cross the freezing point of sap, to assess the effects of $\mathrm{K}$ and $\rho \mathrm{c}$ on $F_{d}$ estimates. To our knowledge, no previous studies have assessed and validated whether alternative temperature ratios can be used to estimate high $F_{d}$. In sap flow research a low-power ratio-based method capable of measuring high and low $F_{d}$ at high precision and accuracy, is highly desirable, but so far, no method seems to perform satisfactorily under contrasting $F_{d}$ ranges. Finally, studies that have previously collected raw data to estimate $F_{d}$ using the HR method, might benefit from the extended measuring range of MHR algorithm, if HR was unable to estimate high flows.

\section{Materials and methods}

\section{Cut-tree experiment set up}

We used a total of eight one-year-old trees ranging from 3-6 cm in diameter (See Table 2), harvested at a local plantation, inside the installations of the National Agricultural Technologies Institute (INTA)

Table 2 Diameters of trees and trunks used in the cut-tree, and freeze/thaw experiments

\begin{tabular}{llll}
\hline Tree/log & Species & Diameter $(\mathrm{cm})$ & Harvest date/time \\
\hline 1 & E. grandis & 5.3 & May 1 2015, 8:00 \\
2 & E. grandis & 6.1 & May 1 2015, 8:00 \\
3 & E. grandis & 3.9 & May 1 2015, 9:00 \\
4 & E. grandis & 6.1 & May 1 2015, 12:00 \\
5 & E. grandis & 4.3 & May 1 2015, 12:00 \\
6 & E. grandis & 6.1 & May 3 2015, 13:00 \\
7 & E. grandis & 5.6 & May 3 2015, 13:00 \\
8 & E. grandis & 5 & May 3 2015, 15:00 \\
1 & A. saccharum & 15 & Dec 10 2017 \\
2 & A. saccharum & 18 & Dec 10 2017 \\
\hline
\end{tabular}


in Concordia, Argentina in 2015 (DOY 123-128). Small trees were selected due to their higher leaf area (Almeida et al. 2007; Forrester et al. 2010) and higher leaf area/sapwood area ratios, which result in fast $F_{d}$. Gravimetric water use $\left(\mathbf{G W U}\right.$, Liters $\left.\mathrm{h}^{-1}\right)$ was estimated for each tree at 15-min intervals from 6AM8PM using a modified cut-tree experiment. (for further details, see: Gutiérrez Lopez et al. 2018). All tree stems were covered with a reflective insulation wrap (ISOLANT $5 \mathrm{~mm}$ ), and sensors were installed in different cardinal directions across the individual trees (two replicates per cardinal direction). Air temperature and relative humidity were monitored with a HMP50 sensor (Campbell Scientific Inc., Logan, UT, USA).

\section{Freeze/thaw experiment}

Two $40 \mathrm{~cm}$ long, approximately $15 \mathrm{~cm}$ DBH Acer saccharum trunks were harvested near the University of New Hampshire campus, in Durham, NH in 2017. Both trunks were sealed with wax and Parafilm on both ends, and each trunk was instrumented with a HP sensor, with equidistant measuring probes, located at $0.5 \mathrm{~cm}$ from the heater, with three measuring points at $0.5,1.65$ and $3 \mathrm{~cm}$ into the sapwood. The freeze/thaw cycles applied to A. saccharum trunks were performed with a commercial freezer that was kept at $-16^{\circ} \mathrm{C}$. The trunks were placed inside the freezer every night after $\sim 19 \mathrm{~h}$ and were removed the following morning $(\sim 8 \mathrm{~h})$ to allow them to warm up at room temperature $\left(26^{\circ} \mathrm{C}\right)$. We also collected data when the trunks were continuously at lower than $-10^{\circ} \mathrm{C}$ or more than $20^{\circ} \mathrm{C}$ for more than $24 \mathrm{~h}$, but we focused on periods with fast freeze/thaw cycles.

Equipment set up and data collection

We used CRBasic 3.8.1 (Campbell Scientific Inc.) to write all scripts needed for data collection (available at https://github.com/joseagl/MHR). Data loggers (CR1000, Campbell Scientific Inc.) and multiplexers (AM1632B, Campbell Scientific Inc.) were used to read and store data for both experiments. All sap flow sensors were connected using low voltage double-shielded cables (75985K63-Mcmaster), and thermocouple cables (TFCC-005-100-Omega), which were extensions to Type-T thermocouples inserted in the temperature sensing probes. The heaters of the HP sensors build out of coiled 36G nichrome wire, had a total resistance of $\sim 19 \Omega \pm 0.2$ and were connected in parallel and controlled with a custom-designed solidstate relay circuit with a maximum current limit of 4 amperes (for further details, see: Gutiérrez Lopez et al. 2018). The cut-tree experiment was powered with a $12 \mathrm{~V} 105 \mathrm{Ah}$ lead-acid battery, and the freeze/ thaw experiment with a $12 \mathrm{~V} 12 \mathrm{Ah}$ lead-acid battery. According to our calculations, the total power released by the heaters (q) was $\sim 168 \mathrm{~W} \mathrm{~m}^{-1}$, calculated as:

$q=\left(\frac{V}{R}\right)^{2} R_{L}$

where $\mathrm{V}$ is the voltage (volts) applied to the heaters, measured after the relay circuits, $\mathrm{R}$ the entire resistance of the heater $(\sim 19 \Omega), \mathrm{R}_{\mathrm{L}}$ the resistance expressed per length $\left(\Omega \mathrm{m}^{-1}\right)$. Temperature $\left(T,{ }^{\circ} \mathrm{C}\right)$ of each of the six thermocouples per sensor was recorded at a scan rate of $\sim 1.5 \mathrm{~s}$ for 143 consecutive seconds, at 15 -min intervals. The full measurement period, or individual data series, consisted of $30 \mathrm{~s}$ of consecutive measurements of initial temperature, followed by a $3 \mathrm{~s}$ heat pulse, and ending with $110 \mathrm{~s}$ of consecutive temperature measurements (94 temperature data points per data series).

\section{Data processing}

All of the data were processed with custom-designed scripts developed in R 3.6.3 (R Core Team, Vienna, Austria) that allowed us to estimate $V_{h}, F_{d}$ and total sap flow $\left(Q, \mathrm{~L} \mathrm{~h}^{-1}\right)$ for both methods. The entire MHR algorithm was implemented on both cut-tree and freeze/thaw data as follows: we first estimated the slope of the initial $30 \mathrm{~s}$ of temperature readings, ignoring the first and last $4 \mathrm{~s}$ to discard potential equilibration period, or memory effects. This was considered the stem temperature trend, and initially all consecutive temperature measurements within a data series were detrended, but unlike similar studies (Vandegehuchte et al. 2015), detrending all data series resulted in additional noise, and consequently we decided not to detrend our data series. Next, we estimated mean temperature for the initial $30 \mathrm{~s}$, and this mean was subtracted from all measurements within the data series to estimate actual temperature increment $\left(\Delta \mathrm{T},{ }^{\circ} \mathrm{C}\right)$. Once each $\Delta \mathrm{T}$ curve was estimated, all measurements were 
run through a simple loess function (Cleveland 1979, 1981) at a span of 0.15 . Once the loess function was estimated, we predicted the $\Delta \mathrm{T}$ curve at a $5 \mathrm{~Hz}$ resolution (i.e., 5 data points per second), and applied a similar process all six thermocouples (three up $\Delta \mathrm{T}_{\mathrm{u}}$, and three down $\Delta \mathrm{T}_{\mathrm{d}}$ from the heating source) inside the stem. For clarification purposes, in Fig. 1 we show the main temperatures, temperature differentials and temperature ratios proposed or used in various heat pulse methods, where $\Delta T_{u}$ is the temperature change after the pulse, at a positive (or negative $\Delta \mathrm{T}_{\mathrm{d}}$ ) distance from the heater, $T_{u}-T_{d}$ the differential temperature, and $\left(\Delta T_{u} /\right.$ $\Delta \mathrm{T}_{\mathrm{d}}$ the ratios of temperature changes after the pulse. To estimate the temperature ratio $\left(\Delta \operatorname{Tmax}_{\mathrm{u}} / \Delta \operatorname{Tmax}_{\mathrm{d}}\right)$ we divided the maximum $\Delta \operatorname{Tmax}_{\mathrm{u}}$ after the heat pulse (see: Fig. 2-A), over the maximum $\Delta \operatorname{Tmax}_{\mathrm{d}}$ of the corresponding lower probe (see: Fig. 2-B). Since both $\Delta$ Tmax rarely occur after $50 \mathrm{~s}$ of the heat pulse even at very fast flows $\left(F_{d}>100 \mathrm{~cm}^{3} \mathrm{~cm}^{-2} \mathrm{~h}^{-1}\right)$, we fixed the timeframe to find $\Delta$ Tmax between $0-50 \mathrm{~s}$ after the pulse. To show that MHR ratios remain stable at fast flows, we divided the $\Delta \operatorname{Tmax}_{\mathrm{u}}$ over every $\Delta \mathrm{T}_{\mathrm{d}}$ after the heat pulse and compared it with the traditional HR method ratios (see: Fig. 2-C\&G). Next, we used the $\Delta \mathrm{T}_{\mathrm{u}}$ data after the pulse, and solved Eq. 4 for $\rho \mathrm{c}$ and $\mathrm{K}$, and estimated $\mathrm{D}$ according to Eq. 7. While $\mathrm{V}_{\mathrm{h}}$ can also be extracted fitting Eq. 4, we limited the curve fitting to $\rho c$ and $\mathrm{K}$ only to avoid overfitting (Lever et al. 2016). Simultaneously $\rho c$ was used to estimate sapwood volumetric water content $\left(\theta_{\mathrm{v}}, \mathrm{m}^{3} \mathrm{~m}^{-3}\right)$, see below for details. Once the temperature ratio $\left(\Delta \operatorname{Tmax}_{\mathrm{u}} / \Delta \operatorname{Tmax}_{\mathrm{d}}\right)$ and D were estimated, heat pulse velocity $\left(V_{h}, \mathrm{~cm} \mathrm{h-1}\right)$ was estimated with Eq. 10 (where $\Delta \mathrm{T}_{\mathrm{u}}$ and $\Delta \mathrm{T}_{\mathrm{d}}$ were the $\Delta \operatorname{Tmax}_{\mathrm{u}}$ and $\Delta \operatorname{Tmax}_{\mathrm{d}}$, respectively) and corrected for wounding $\left(\boldsymbol{V}_{\boldsymbol{c}}, \mathrm{cm} \mathrm{h}-1\right)$ according to Burgess et al. (2001) using the following equation where b, c, and d, are the wounding parameters:

$V_{c}=b V_{h}+c V_{h}^{2}+d b V_{h}^{3}$

We also note that because wound correction functions were originally derived for the HR method, we plan in future works to examine wound correction functions specifically for the MHR; in the meantime we note however, that the two algorithms are closely correlated over a considerable common range. $V_{c}$ was converted
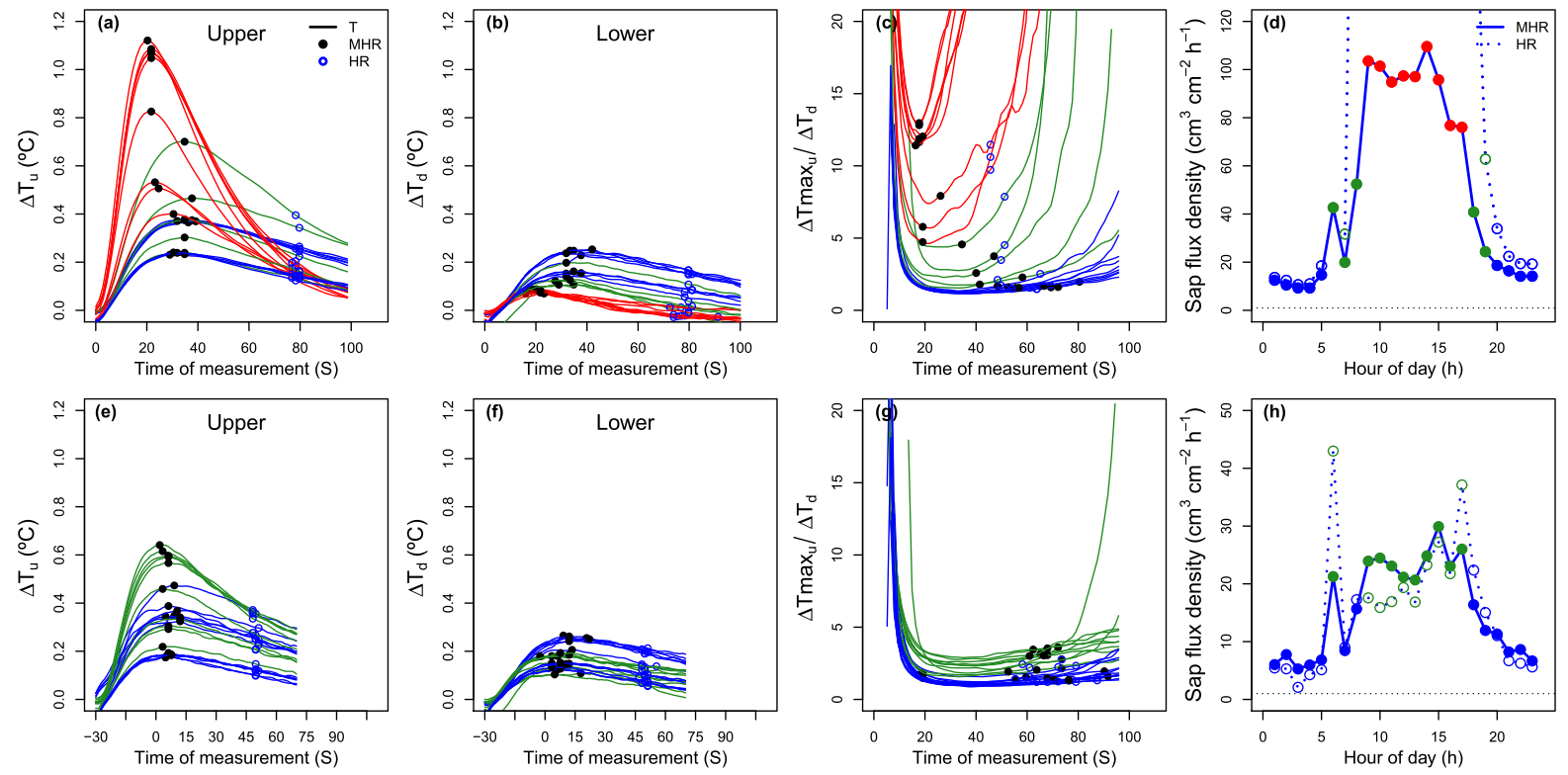

Fig. 2 Use of the maximum heat ratio (MHR) algorithm. For visualization purposes, $\Delta \mathrm{T}\left({ }^{\circ} \mathrm{C}\right)$ have been color-coded within different $F_{d}$ ranges (blue $<20$, green $20-60$, red $>60$ $\left.\mathrm{cm}^{3} \mathrm{~cm}^{-2} \mathrm{~h}^{-1}\right)$. a: temperature increments $\left(\Delta \mathrm{T},{ }^{\circ} \mathrm{C}\right)$ before and after the heat pulse in the upper probe, $\mathbf{b}: \Delta \mathrm{T}\left({ }^{\circ} \mathrm{C}\right)$ in the lower probe, $\mathbf{c}$ : temperature ratios obtained when the maximum $\Delta \mathrm{T}$ in the upper probe, is divided over each $\Delta \mathrm{T}$ in the lower probe
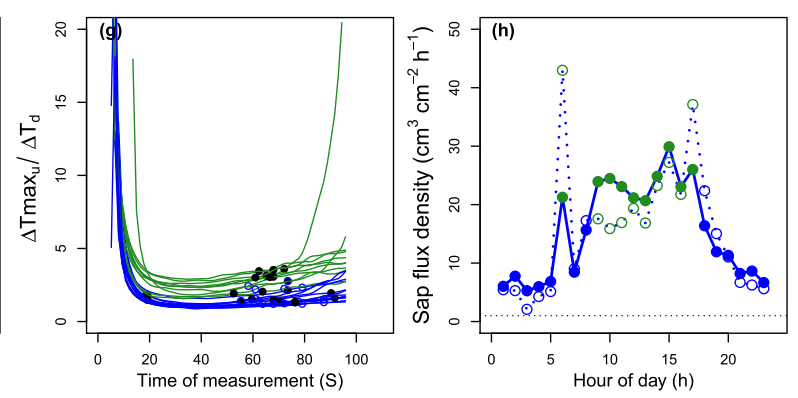

(After the pulse only. $\mathrm{R}_{\mathrm{T}}>30$ and $<1$ were ignored). The black circles correspond to the $\mathrm{R}_{\mathrm{T}}$ estimated using MHR and blue open circles correspond to HR. d: Sap flux density $\left(F_{d}, \mathrm{~cm}^{3}\right.$ $\mathrm{cm}^{-2} \mathrm{~h}^{-1}$ ) estimated with temperature ratios obtained using MHR and HR methods. In the bottom panels (e, f, g, h) we show the same process, but for a sensor with a lower range of sap flux densities (within the measurement range of HR) 
to $F_{d}$ according to Vandegehuchte and Steppe (2013) using:

$F_{d}=\frac{\rho_{w}}{\rho_{s}}\left(\theta_{v}+\frac{C_{w}}{C_{s}}\right) V_{c}$

where $\rho_{\mathrm{w}}$ is the density of the sapwood $\left(\mathrm{kg} \mathrm{m}^{-3}\right)$, $\rho_{\mathrm{s}}$ the density of water $\left(\mathrm{kg} \mathrm{m}^{-3}\right), \theta_{v}$ the volumetric water content of the sapwood $\left(\mathrm{m}^{3} \mathrm{~m}^{-3}\right), \mathrm{C}_{\mathrm{w}}$ the specific heat capacity of sapwood $\left(\mathrm{J} \mathrm{kg}^{-1} \mathrm{~K}^{-1}\right)$, and $\mathrm{C}_{\mathrm{s}}$ the specific heat capacity of sap (assumed to be the same as water). $F_{d}$ was estimated for both MHR and the traditional HR method by Burgess et al. (2001) (Fig. 2-D\&H). To estimate $\theta_{v}$, we used the estimated $\rho c$ (i.e., Eq. 4 for each $\Delta \mathrm{T}_{\mathrm{u}}$ curve and solving for $\mathrm{K}$ and $\rho \mathrm{c}$ ) and since $\theta_{v}$ is directly proportional to $\rho \mathrm{c}$ (Campbell et al. 1991):

$\rho c=c_{s} \rho_{s} \theta_{v}+c_{w} \rho_{w}$

Solving for $\theta_{v}$ yields:

$\theta_{v}=\frac{\rho c-\rho_{w} c_{w}}{\rho_{s} c_{s}}$

Both $\mathrm{K}$ and $\rho \mathrm{c}$ were estimated for each 15-min period as shown in Fig. 3, but D used in Eq. 10 was the value that corresponded to zero flow (zero $F_{d}$ in Fig. 3-a-b). For $F_{d}>0, \rho c$ used in Eq. 15, and subsequently in Eq. 13 were the 15 -min interval estimates (Fig. 3). Finally, since we fitted Eq. 4 at three positions within the sapwood, we focused on D estimated in the outer depth at zero and slow flows, primarily because deeper positions rarely reached true zero flow during our study, consequently D used on other sapwood depths is considered an approximation. Each depth had its own $\theta_{v}$ estimated at 15-min intervals, although for most depths, $\theta_{v}$ remained relatively constant (see Fig. 3-e). To estimate whole tree water use ( $Q, \mathrm{~L}$ per hour) for both MHR and HR in the cuttree experiment, we fitted the following radial profile equation to address the commonly known changes in $F_{d}$ with sapwood depth (Berdanier et al. 2016; Caylor and Dragoni 2009; Granier et al. 1994; Wullschleger and King 2000): model. Sapwood depth was normalized and split into 100 bins, and we fitted the model across the three $F_{d}$ estimates for each sapwood depth monitored. $F_{d}$ and sapwood area $\left(\mathrm{As}, \mathrm{cm}^{2}\right)$ were predicted for each of the 100 bins, and sap flow $\left(\mathrm{Q}, \mathrm{L} \mathrm{h}^{-1}\right)$ was estimated by integrating their product. A radial profile equation was fitted for every measurement time (i.e., 96 per day) for each tree and stem. All curve fitting process were performed in R 3.6.3 (R Core Team, Vienna, Austria) using the lme4 (Bates et al. 2015) and expint (Goulet 2016) packages. The freeze-thaw experiment focused on $F_{d}$ only and no radial profiles were fitted.

\section{Statistical analyses}

To compare sap flux density estimates derived with MHR and HR algorithms, we focused on linear relationships. The first set of analysis focused on $F_{d}$ whereby linear regressions and F-tests were performed between MHR and HR for each individual day of study (DOY: 123 through 128) and combining all the days, these were used to derive estimates of the ranges at which MHR and HR have a linear relationship. These analyses were performed for both cut-tree and freeze/thaw experiments. The second set of data analyses focused on sap flow $\left(Q, \mathrm{~L} \mathrm{~h}^{-1}\right)$ estimated with MHR and HR, ad their relationship to measured gravimetric water use $\left(\mathrm{GWU}, \mathrm{L} \mathrm{h}^{-1}\right)$. These analyses were also performed by day of study (DOY: 123 through 126) and combining all dates. All analyses were performed using base functions in R 3.6.3.

\section{Results}

Measurable $F d$ range of $\mathrm{HR}$ and MHR algorithms

Using data from our cut-tree experiment, we were able to measure a $F_{d}$ range from $0-45\left(\mathrm{~cm}^{3}\right.$ $\mathrm{cm}^{-2} \mathrm{~h}^{-1}$ ) using the HR algorithm with a minimal presence of outliers, and a range of $0-130\left(\mathrm{~cm}^{3}\right.$ $\mathrm{cm}^{-2} \mathrm{~h}^{-1}$ ) using MHR on one-year-old E. grandis trees ranging from 3 to $6 \mathrm{~cm}$ in diameter (Fig. 4-b).

$F_{d}=\beta 0\left(\beta 1-\exp \left(-\beta 1 D_{s}\right)\right) *\left(\beta 0 * \exp \left(-\beta 2 D_{s}\right) * x+\left(\beta 3-\beta 4 D_{s}\right)\right)$

were $D_{s}$ is the normalized sapwood depth, and $\beta 0, \beta 1, \beta 2, \beta 3$, and $\beta 4$ the parameters fitted for the
We did not observe significant under or overestimations of $Q$ for each algorithm within these ranges 

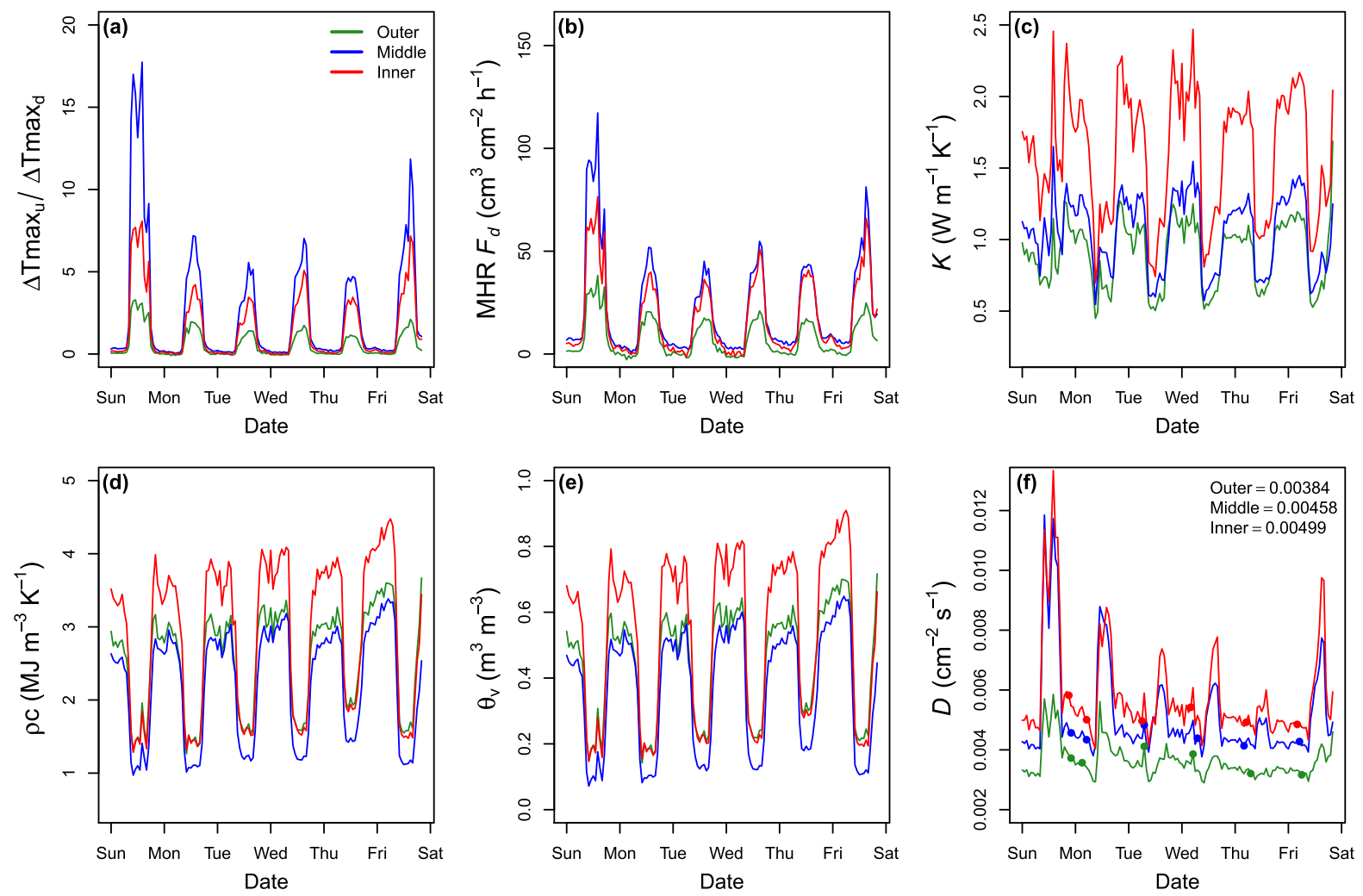

Fig. 3 a: Heat ratios $\left(\Delta \operatorname{Tmax}_{\mathrm{u}} / \Delta \mathrm{Tmax}_{\mathrm{d}}\right)$, b: sap flux density $\left(F_{d}, \mathrm{~cm}^{3} \mathrm{~cm}^{-2} \mathrm{~h}^{-1}\right)$ estimated using maximum heat ratio, c: thermal conductivity $\left(\mathrm{K}, \mathrm{W} \mathrm{m} \mathrm{m}^{-1} \mathrm{~K}^{-1}\right)$, d: volumetric heat capacity ( $\left.\mathrm{pc}, \mathrm{MJ} \mathrm{m}^{-3} \mathrm{~K}^{-1}\right)$ and $\mathbf{e}$ : volumetric water content $\left(\theta_{\mathrm{v}}\right.$, $\mathrm{m}^{3} \mathrm{~m}^{-3}$ ) and thermal diffusivity $\left(\mathrm{D}, \mathrm{m}^{2} \mathrm{~s}^{-1}\right.$ ) estimated for each of the three sapwood depth positions (Outer, Middle, Inner) at 15-min intervals, shown as hourly means. Closed circles in f:, highlight thermal diffusivity at times when sap flux density was zero. Data used in this graph corresponds to tree 2

\section{Comparison between MHR and HR algorithms}

(equipment malfunction resulted in underestimated $Q$ on some trees on DOY 124-125; see discussion for further details). The maximum measurable $F_{d}$ ranges estimated with MHR varied by tree, but it was often greater than $100 \mathrm{~cm}^{3} \mathrm{~cm}^{-2} \mathrm{~h}^{-1}$ (Fig. 4-b). Some trees showed a reduction in $F_{d}$ from the first to the second day of our experiment. This reduction was in some cases close to $50 \%$, for example Tree 2 , reduced from $130\left(\mathrm{~cm}^{3} \mathrm{~cm}^{-2} \mathrm{~h}^{-1}\right.$, estimated with MHR) to around 60 from DOY 123 to DOY 124. Our analysis suggests that these reductions were not associated with hydraulic cavitation, in part because except for tree $8, \theta_{v}$ showed a normal daily cycle on all trees (e.g. Figure 3-e).
An initial comparison between $\mathrm{HR}$ and MHR showed that ratios estimated with HR were noisier and had a higher number of aberrant positive and negative values (i.e., values with an absolute value greater than three standard deviations), especially at high transpiration rates (Fig. 4-B\&C). Conversely MHR ratios appeared more stable, and we did not observe extremely high or negative values, especially when the $F_{d}$ range was higher than 60 $\left(\mathrm{cm}^{3} \mathrm{~cm}^{-2} \mathrm{~h}^{-1}\right)$. Estimated $F_{d}$ derived from MHR and HR algorithms were similar within a range of $0-45 \mathrm{~cm}^{3} \mathrm{~cm}^{-2} \mathrm{~h}^{-1}\left(\mathrm{R}^{2}=0.90\right.$, linear regression: $\mathrm{HR}=0.56+1.063 * \mathrm{MHR}$. Figure $5 \mathrm{a}, \mathrm{b}, \mathrm{c})$. Above this 

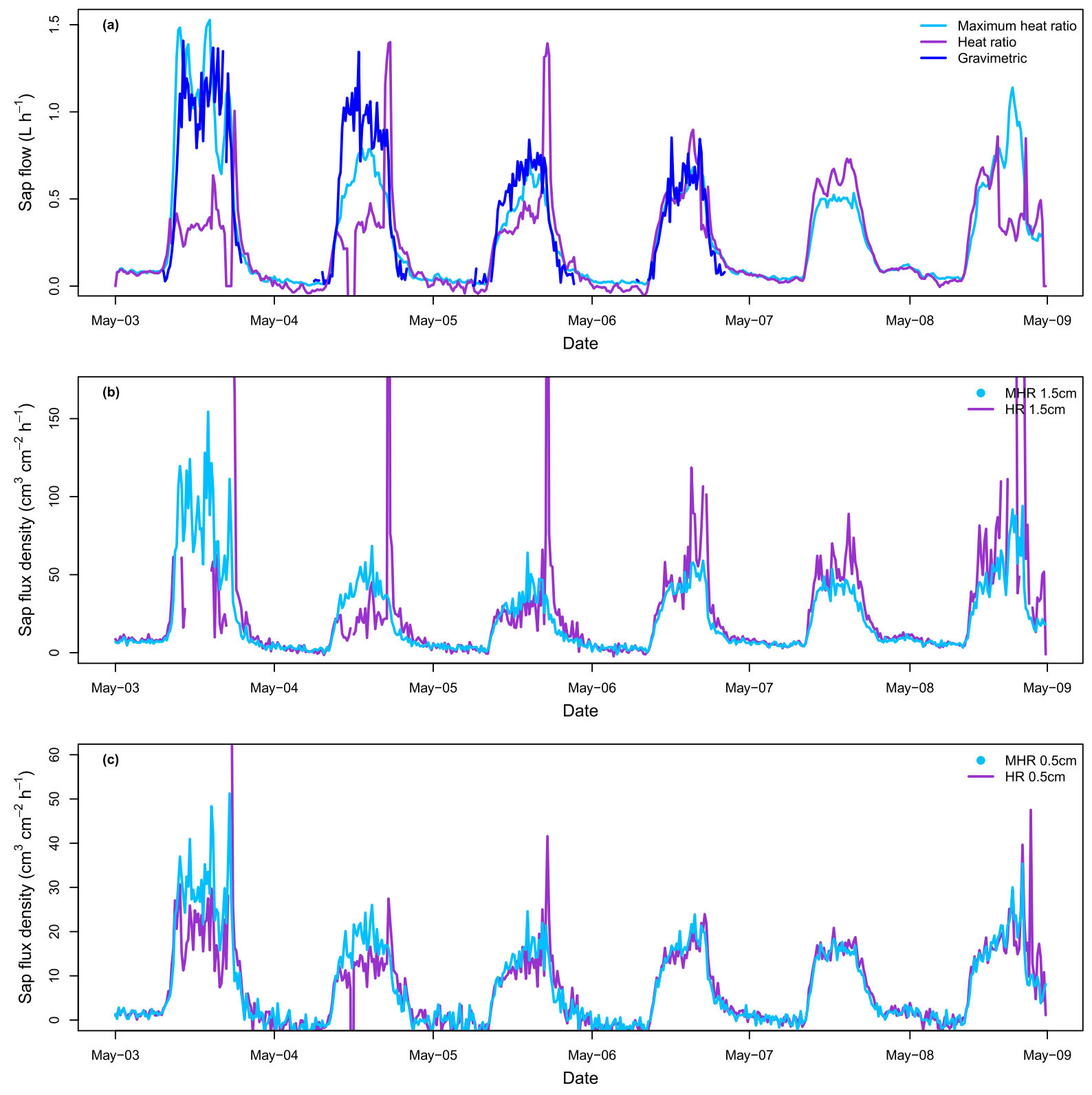

Fig. 4 Sap flow (Q, $\left.\mathrm{L} \mathrm{d}^{-1}\right)$ and sap flux density $\left(F_{d}, \mathrm{~cm}^{3}\right.$ $\mathrm{cm}^{-2} \mathrm{~h}^{-1}$ ) estimated with the maximum heat ratio (MHR) and heat ratio (HR) methods. a: sap flow $\left(\mathrm{Q}, \mathrm{L} \mathrm{h}^{-1}\right)$ estimated using the maximum heat ratio method (MHR) and the tradi-

threshold, the $F_{d}$ estimates differed significantly, mainly due to the abnormally high or low estimates of HR. The correlation between MHR and HR varied within each day, and except for the first day of our experiment, seemed to be driven by the rate change in $V P D$ (i.e., the net $V P D$ change from 6AM to max $V P D)$. For example, on DOY 124, MHR and HR tional heat ratio (HR) methods compared with gravimetric measurements, and sap flux density $\left(F_{d}, \mathrm{~cm}^{3} \mathrm{~cm}^{-2} \mathrm{~h}^{-1}\right)$ estimated with each method at $1.5 \mathrm{~cm} \mathrm{~b}$ : and $0.5 \mathrm{~cm} \mathbf{c}$ : into the sapwood. Data used in this graph corresponds to tree 2

were correlated within a shorter range (approx. 0-20 $\mathrm{cm}^{3} \mathrm{~cm}^{-2} \mathrm{~h}^{-1}$ ), compared DOY 126 (approx. 0-50 $\mathrm{cm}^{3} \mathrm{~cm}^{-2} \mathrm{~h}^{-1}$, Fig. 5).

Differences between MHR and HR were also dependent on the time of the day. From 0 to $12 \mathrm{~h}$ when $F_{d}$ was lower than $40 \mathrm{~cm}^{3} \mathrm{~cm}^{-2} \mathrm{~h}^{-1}$, the correlation between $\mathrm{HR}$ and MHR was stronger 

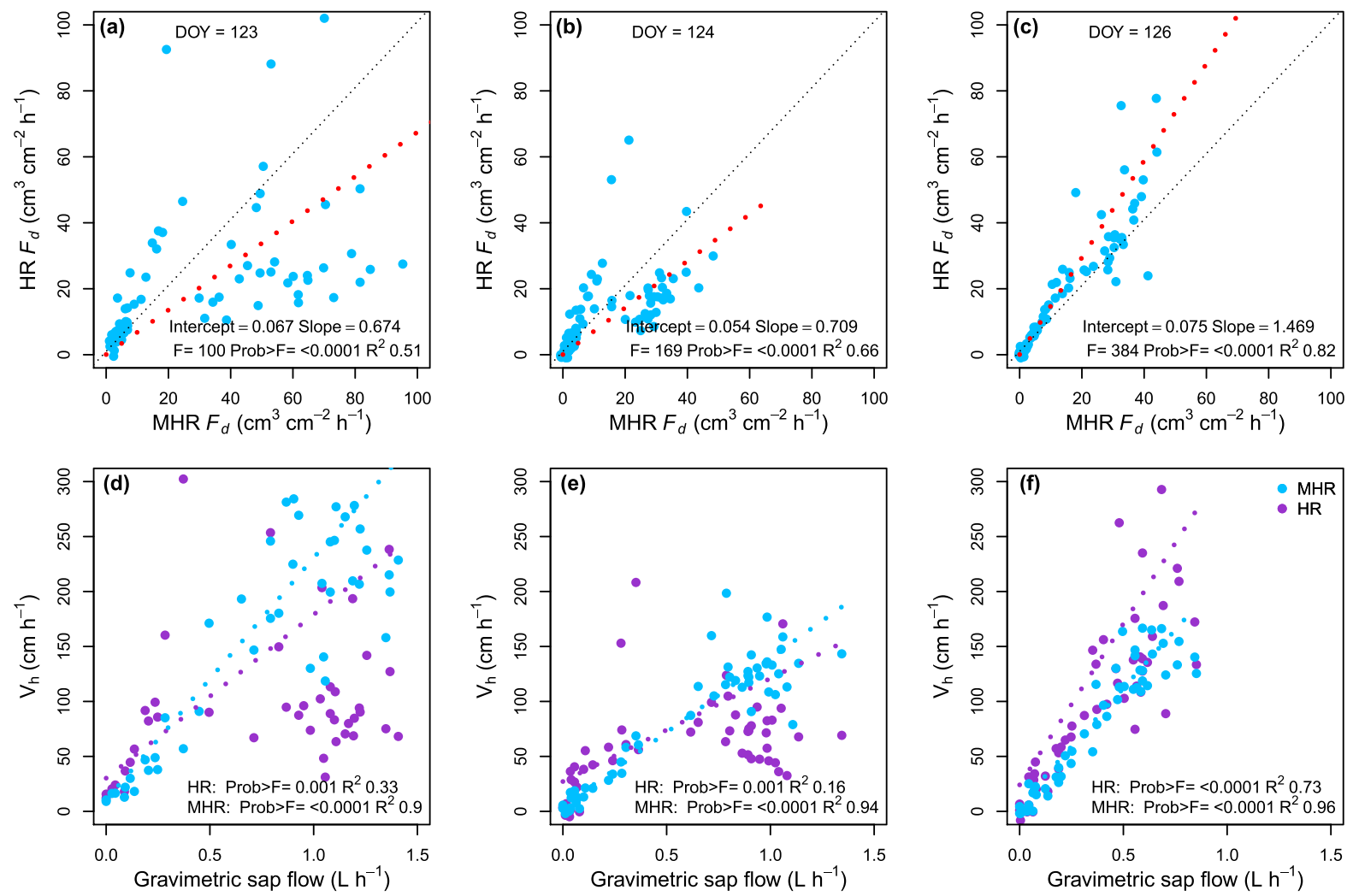

Fig. 5 a, b, c: Correlation of sap flux density $\left(F_{d}, \mathrm{~cm}^{3}\right.$ $\mathrm{cm}^{-2} \mathrm{~h}^{-1}$ ) estimates between maximum heat ratio (MHR) and heat ratio (HR) algorithms. Dotted red line represents the line of best fit between MHR and HR. d, e, f: Correlation between

$\left(\mathrm{HR}=-0.1303+1.074 * \mathrm{MHR}, \quad \mathrm{R}^{2}=0.96\right) \quad$ than between $13-24 \mathrm{~h} \quad(\mathrm{HR}=2.192+1.02 * \mathrm{MHR}$, $\mathrm{R}^{2}=0.79$ ) (data not shown). Additionally, the HR algorithm showed an overestimation memory effect (average: $5 \mathrm{~cm}^{3} \mathrm{~cm}^{-2} \mathrm{~h}^{-1}$ ) with respect to MHR on the second half of the day $(13-24 \mathrm{~h})$ primarily in trees that had $F_{d}$ greater than $\sim 50 \mathrm{~cm}^{3} \mathrm{~cm}^{-2} \mathrm{~h}^{-1}$. This memory effect was characterized by an overestimation where $F_{d}$ that remain higher even after $F_{d}$ returned to the measurable range of the HR method. However, since no overestimation was observed when $F_{d}$ was lower than 50, this suggests that this memory effect occurs only when $F_{d}$ falls outside the measurement range of HR. Finally, the MHR temperature ratio $\left(\Delta \operatorname{Tmax}_{\mathrm{u}} / \Delta \mathrm{Tmax}_{\mathrm{d}}\right)$, and the $\mathrm{V}_{\mathrm{h}}$ estimated from it using Eq. 10, showed a stronger linearity with GWU, compared with the temperature ratios and $V_{h}$ from HR (Fig. 5-d,e, f). mean heat pulse velocity $\left(\mathrm{V}_{\mathrm{h}}, \mathrm{cm} \mathrm{h}^{-1}\right)$ across sapwood depths estimated with Eq. 10, and gravimetric water use (GWU, L $\mathrm{h}^{-1}$ ). Data used in this graph corresponds to tree 2, and similar patterns were observed in other trees

Whole tree sap flow estimates $\left(Q, \mathrm{~L} \mathrm{~h}^{-1}\right)$ from MHR and HR algorithms had similar patterns to those of $F_{d}$ (Fig. 6), particularly at low water use rates. However, since $Q$ is integrated from different annuli within the sapwood, and some annuli had $F_{d}$ outside the measurable range of $\mathrm{HR}$, the underestimation observed using HR was the result of missing values, caused by the limited $F_{d}$ measurement range of this algorithm (as seen in Fig. 4-a). Consequently, HR showed underestimations of mean whole-tree sap flow when $F_{d}$ was often outside the measuring range of $\mathrm{HR}$. Overall, $Q$ estimates from MHR had a higher correlation $\left(\mathrm{b} 0=0.01, \mathrm{~b} 1=0.80, \mathrm{R}^{2}=0.91\right)$ with mean GWU compared to HR ( $\mathrm{b} 0=0.02, \mathrm{~b} 1=0.53$, $\mathrm{R}^{2}=0.68$ ), with differences by day resulting from low $Q$ estimates from HR. Due to power issues during DOY 124 and 125 , some Q estimates appeared lower than GWU, however, this does not affect our results, not our interpretation of the data. 

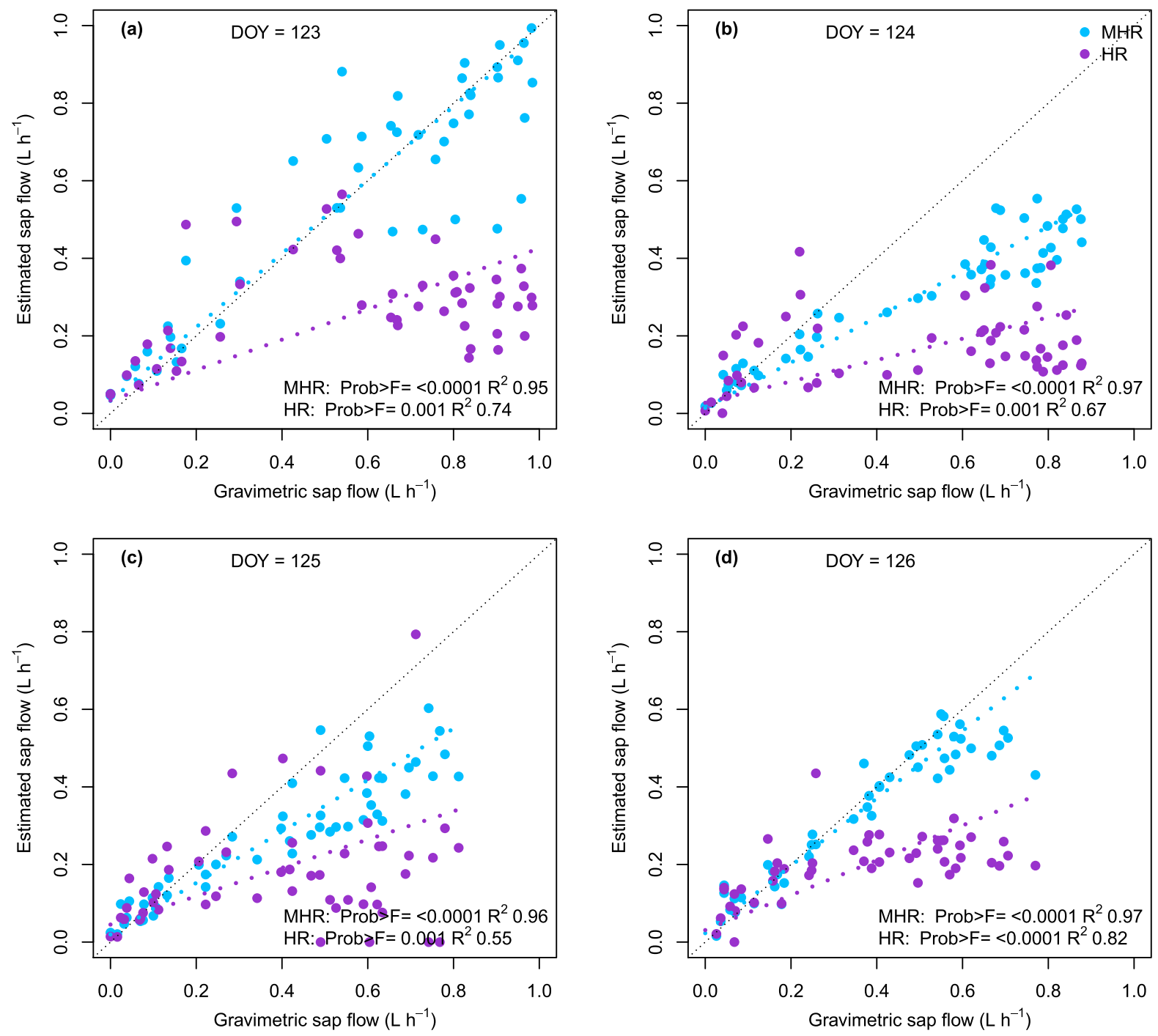

Fig. 6 Average whole-tree transpiration $\left(Q \mathrm{~L} \mathrm{~h}^{-1}\right)$ estimated with maximum heat ratio (MHR, blue dots) and heat ratio (HR, purple) methods, compared with mean gravimetric water use.

\section{Freeze/thaw experiment}

For the A. saccharum trunks that we subjected to freeze/thaw cycles, we observed a total $F_{d}$ range from -30 to $50\left(\mathrm{~cm}^{3} \mathrm{~cm}^{-2} \mathrm{~h}^{-1}\right)$. Under these conditions, MHR and HR had nearly identical $F_{d}$ estimates during freezing $\left(\mathrm{R}^{2}=0.97\right.$, Fig. 7), however, during thawing HR showed lower $F_{d}$, compared with MHR (up to $10 \mathrm{~cm}^{3} \mathrm{~cm}^{-2} \mathrm{~h}^{-1}$ ). Both MHR and HR were quite stable during both freezing and thawing, but most noise and occasional outliers were observed
Mean gravimetric water use was estimated using all monitored trees. Dotted lines represent the best linear fit between MHR and HR. Data used in this graph corresponds to tree 2

during thawing when the stem temperature increased rapidly (Fig. 7). Most flows occurred during thawing $\left(-1.2^{\circ} \mathrm{C}\right.$ to $\left.-0.2^{\circ} \mathrm{C}\right)$, and while positive flows occurred mainly during thawing, the flow direction varied among sapwood depths of the same trunk, with overall positive (towards the canopy) in shallower depths, and negative flows (towards the roots) in deeper sapwood depths. When the trunks were left for more than 24 outside the freezer at room temperature $\left(26^{\circ} \mathrm{C}\right)$, all sap flow ceased and both MHR and HR registered $F_{d}$ insignificantly different from zero. A similar pattern 

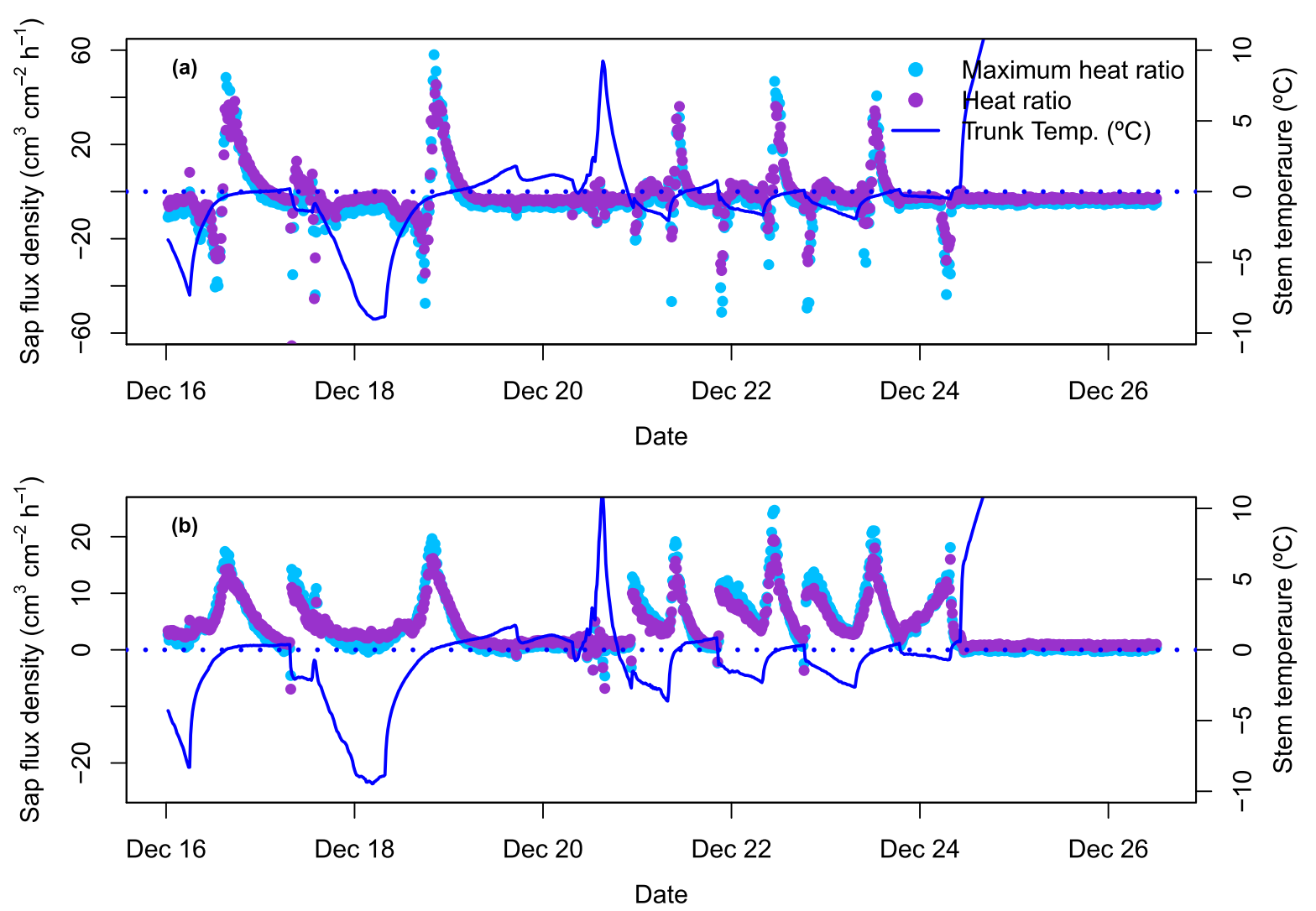

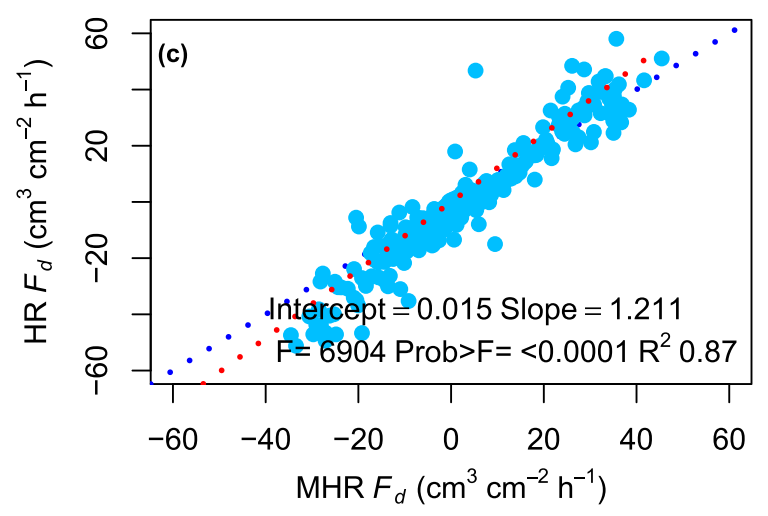

Fig. 7 Mean sap flux density $\left(F_{d}, \mathrm{~cm}^{3} \mathrm{~cm}^{-2} \mathrm{~h}^{-1}\right)$ estimated at three sapwood depths: $0.5,1.6$ and $3 \mathrm{~cm}$ in two A. saccharum trunks with the maximum heat ratio (MHR) and the heat ratio (HR) methods $(\mathbf{a}=$ stem $1 ; \mathbf{b}=$ stemtrunk 2$)$, and $\mathbf{c}$, $\mathbf{d}$ : linear relationship between MHR and HR methods for stems 1 and

was observed when the trunks were left continuously at low $\left(-10^{\circ} \mathrm{C}\right)$ temperatures inside the freezer. At low $F_{d}$, thermal diffusivity $\left(\mathrm{D}, \mathrm{cm}^{2} \mathrm{~s}^{-1}\right)$ and volumetric heat capacity $\left(\rho \mathrm{c}, \mathrm{MJ} \mathrm{m}^{-3} \mathrm{~K}^{-1}\right.$ ) remained relatively

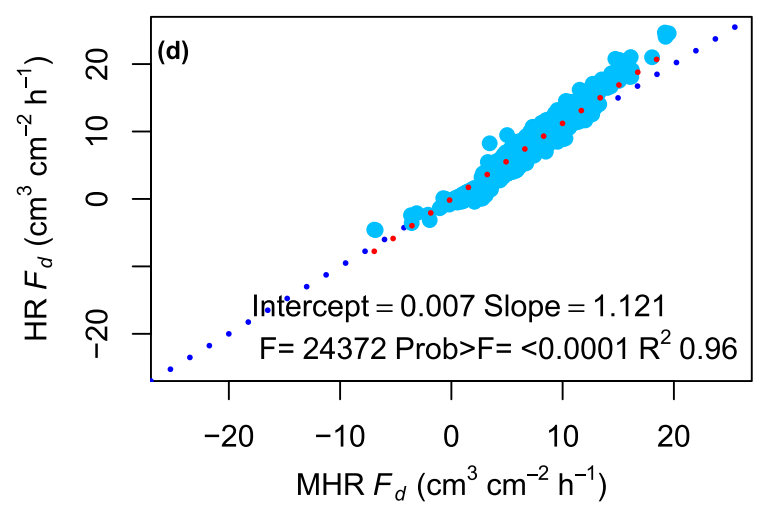

2, respectively. In all cases, we show the mean for all three sapwood depths monitored. Trunk temperature (shown in blue solid lines) is averaged across all monitored sapwood depths $(0.5,1.6$, and $3 \mathrm{~cm})$. Dotted line represented the best linear fit between MHR and HR

constant with changes in temperature in the cut-tree experiment, however, for the freeze/thaw experiment $\mathrm{D}$ and consequently $\rho \mathrm{c}$, showed a phase shift when temperature was below $0^{\circ} \mathrm{C}$ (Fig. 8). D used in Eq. 10 

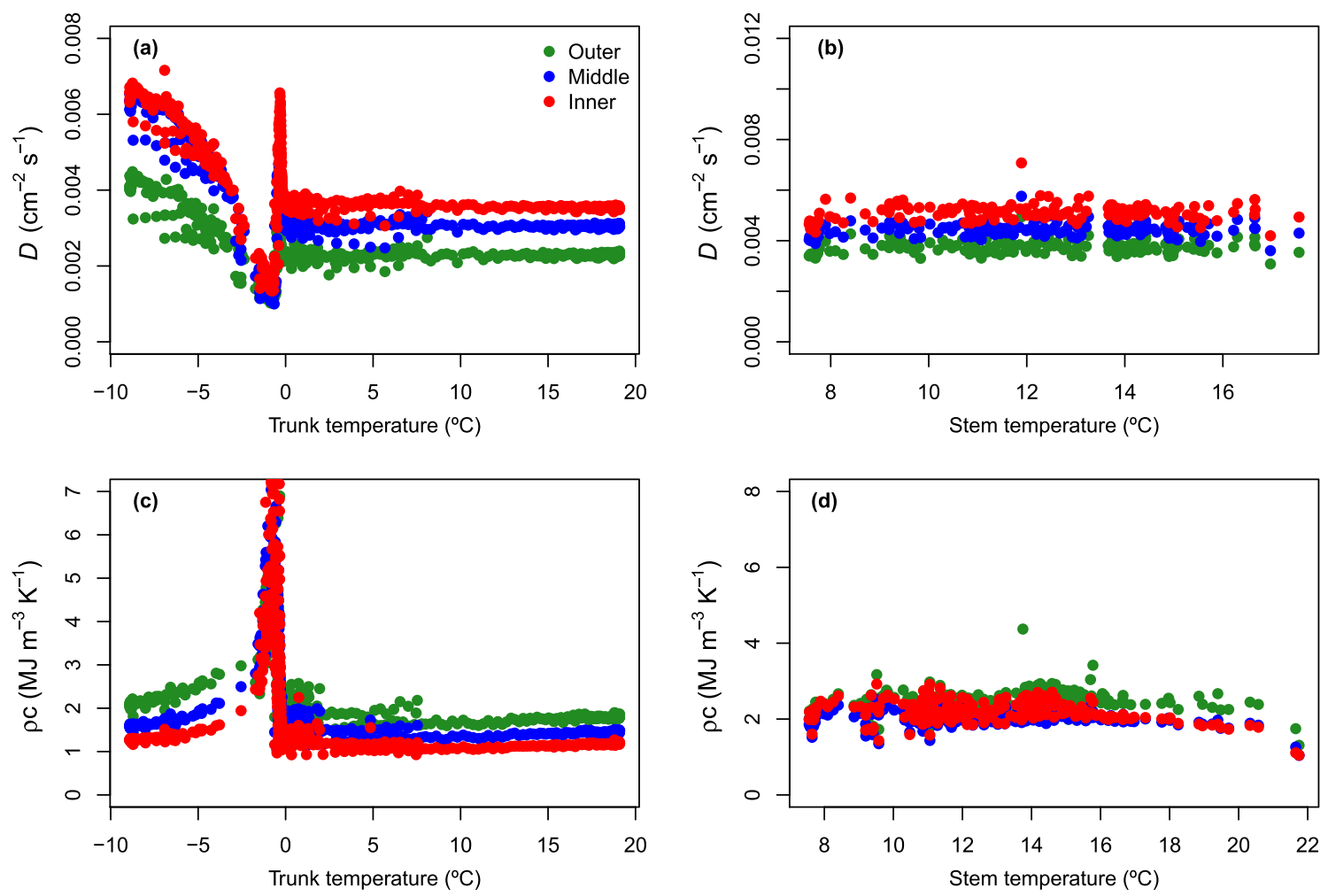

Fig. 8 Relationship between temperature and thermal diffusivity $\left(\mathrm{D}, \mathrm{m}^{2} \mathrm{~s}^{-1}\right)$, and volumetric heat capacity $\left(\mathrm{pc}, \mathrm{MJ} \mathrm{m}^{-3} \mathrm{~K}^{-1}\right.$ ), estimated at three different depths inside the sapwood. (a) and (c) trunk 1 from our freeze/thaw experiment, (b) and (d) cor-

respond to tree 1 from the tree-cut experiment. All data was filtered to show values corresponding to sap flux density lower than $5 \mathrm{~cm}^{3} \mathrm{~cm}^{-2} \mathrm{~h}^{-1}$

was kept constant, but the $\rho$ c used in Eq. 15 was estimated at 15-min intervals, which was later used to estimate $F_{d}$ in Eq. 13 and increased $F_{d}$ estimates.

\section{Discussion}

Measurable range of $F_{d}$, and expansion using alternative algorithms

Using the same wood properties (e.g., moisture content, density, etc.) and the same heat pulse velocity, $F_{d}$ estimated with Eq. 13 is similar to sap velocity $\left(\mathrm{V}_{\mathrm{s}}, \mathrm{cm}\right.$ $\mathrm{h}^{-1}$ ) estimated following Burgess et al. (2001). Thus, we consider it appropriate to compare our results with other studies that have focused on $\mathrm{V}_{\mathrm{s}}$ as a unit of flow. In our cut-tree experiment, on average $Q$ estimated with the HR method was strongly correlated to GWU when $F_{d}$ was within a range of $0-45 \mathrm{~cm}^{3} \mathrm{~cm}^{-2} \mathrm{~h}^{-1}$, and in some trees within higher ranges (up to $0-60$ on Tree 2). The

MHR algorithm allowed for a wider range of $F_{d}$. On the first day of our experiment, we estimated $F_{d}$ up to $140 \mathrm{~cm}^{3} \mathrm{~cm}^{-2} \mathrm{~h}^{-1}$, and up to 120 on DOY 126, which is considerably higher than the measured range achievable with HR. A $F_{d}$ range of $0-130 \mathrm{~cm}^{3} \mathrm{~cm}^{-2} \mathrm{~h}^{-1}$ is higher than the maximum $\mathrm{V}_{\mathrm{s}}$ observed in other studies and tree species: $83 \mathrm{~cm} \mathrm{~h}^{-1}$ in E. regnans (Vertessy et al. 1997), $33 \mathrm{~cm} \mathrm{~h}^{-1}$ in P. patula (Alvarado-Barrientos et al. 2013), $75 \mathrm{~cm} \mathrm{~h}^{-1}$ in L. tulipifera (Wullschleger and King 2000)], and even the maximum $\mathrm{V}_{\mathrm{s}}$ reported for E. grandis: $60 \mathrm{~cm} \mathrm{~h}^{-1}$ in 4-year old plantations (Benyon 1999), and $60 \mathrm{~cm} \mathrm{~h}^{-1}$ in 26 year-old plantations (Kallarackal 2010). On grapevines, where the LAI to sapwood area ratios are extremely high, studies have measured maximum $\mathrm{V}_{\mathrm{s}}\left(\mathrm{cm} \mathrm{h}^{-1}\right)$ of 110 using the Tmax method (Intrigliolo et al. 2009), which is still within the range of $F_{d}$ measured with MHR.

The main reason for the low measurement $F_{d}$ range of $\mathrm{HR}$, is the $60 \mathrm{~s}$ waiting period after the release of the heat pulse before making temperature 
measurements to estimate the temperature ratio. At $F_{d}$ higher than approximately $55 \mathrm{~cm}^{3} \mathrm{~cm}^{-2} \mathrm{~h}^{-1}$, the mean $\Delta \mathrm{T}$ from 60 to $100 \mathrm{~s}$ in the lower thermocouple is close to, or already zero (see Fig. 1 and Fig. 2). Under these conditions, dividing mean $\Delta \mathrm{T}$ from 60 to $100 \mathrm{~s}$ between the upper and lower probes, results in a fictitious high or low temperature ratio and equivalent $F_{d}$. The $60-100 \mathrm{~s}$ was initially selected because of the linearity of the temperature ratio, and while they become linear as early as $40 \mathrm{~s}$ after the pulse, this only seems to occur under slow flows (e.g., $F_{d}<55$ $\mathrm{cm}^{3} \mathrm{~cm}^{-2} \mathrm{~h}^{-1}$ ) (see Fig. 2-c\&g). Selecting the $\Delta$ Tmax after the pulse in both upper and lower probes, to estimate the temperature ratio $\left(\Delta \operatorname{Tmax}_{\mathrm{u}} / \Delta \operatorname{Tmax}_{\mathrm{d}}\right)$ avoids the fictitious $F_{d}$. In the absence of sap flow, upperand lower-probe $\Delta$ Tmax after the pulse are nearly identical, and temperature ratio estimated from them results in zero $F_{d}$. As $F_{d}$ increases, $\Delta \operatorname{Tmax}_{\mathrm{u}}$ increases,

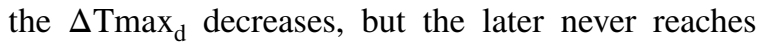
zero (see Fig. 1-d and Fig. 2-c\&g). Other $\Delta \mathrm{T}_{\mathrm{u}} / \Delta \mathrm{T}_{\mathrm{d}}$ ratios should also work, but the only one that seems to remain stable over a large range of $F_{d}$ ranges is the $\Delta \operatorname{Tmax}_{\mathrm{u}} / \Delta \operatorname{Tmax}_{\mathrm{d}}$. The differential $\mathrm{T}_{\mathrm{u}}-\mathrm{T}_{\mathrm{d}}$, which has also been proposed as an alternative to estimate $\mathrm{Vh}$, seems to capture well fast flows, but it is difficult to estimate slow flows with it (see Fig. 1-c). Previously Vandegehuchte et al. (2015) showed that shifting the time frame for mean $\Delta \mathrm{T}$ from $20-60 \mathrm{~s}$, instead of 60-100 s, increase the measurement range of HR; however, when we applied this time frame to our data, $F_{d}$ estimates were excessively high, and $Q$ estimated from them did not match our gravimetric measurements. This led us to believe that shifting the time frame is valid, as long as the flows remain slow (i.e., under $20 \mathrm{~cm}^{3} \mathrm{~cm}^{-2} \mathrm{~h}^{-1}$ ). An additional advantage of the $\Delta \operatorname{Tmax}_{\mathrm{u}} / \Delta \mathrm{Tmax}_{\mathrm{d}}$ ratio, is that within a single $\Delta \mathrm{T}$ (above or below the heater) curve $\Delta$ Tmax is directly proportional to D (see Eq. 5), and since $F_{d}$ is constant from the lower to the upper probe, the timing at which these two $\Delta \operatorname{Tmax}_{\mathrm{u}}$ and $\Delta \operatorname{Tmax}_{\mathrm{d}}$ occur is very similar, particularly within slow and medium flows (as shown in Fig. 2-a,b,e,f), making it a robust ratio that deals well with convection at slow flows, and conduction at fast flows. We also tested temperature ratios where $\Delta \operatorname{Tmax}_{\mathrm{d}}$ was picked at the time when $\Delta \operatorname{Tmax}_{\mathrm{u}}$ occur, and the only difference observed were higher ratios, and $F_{d}$ during the peak of the flows. This was caused because at very fast flows, there is a greater transport of convective heat forcing $\Delta \operatorname{Tmax}_{\mathrm{u}}$ to occur at an earlier time than $\operatorname{Tmax}_{\mathrm{d}}$. However, fast $F_{d}$ estimates from this approach did not match GWU estimates.

The ability to measure fast $F_{d}$ is of great importance in ecological and physiological research. Studies often require comparing the same species at different developmental stages, which can result in significantly different ranges of $F_{d}$. For example, Forrester et al (2010) observed fast $F_{d}$ in two-year-old Eucalyptus globulus trees compared to eight-year-old trees (average of 13 to $6 \mathrm{~cm} \mathrm{~h}^{-1}$ ). According to their results these changes in $F_{d}$ were strongly associated with changes with age and the ratio between LAI and sapwood area $\left(\mathbf{L A I} / \mathbf{A}_{\mathbf{S}}\right)$. Other studies using various sap flow sensors have reported similar patterns of fast $F_{d}$ when the LAI/As ratios are high (Alsheimer et al. 1998; Delzon and Loustau 2005; Dye et al. 1996; Forrester et al. 2010; Kostner et al. 2002). Nonetheless, studies reporting fast $F_{d}\left(>100 \mathrm{~cm}^{3} \mathrm{~cm}^{-2} \mathrm{~h}^{-1}\right)$ on whole rooted trees are rare, likely in part due to the difficulty in conducting these measurements. Conversely, in artificial setups commonly used in sensor validation experiments, fast $F_{d}$ estimates are commonly observed. For example, Vandegehuchte and Steppe (2012b) using the Sapflow + method, estimated $\mathrm{V}_{\mathrm{s}}$ close $150 \mathrm{~cm} \mathrm{~h}^{-1}$ on artificial columns filled with sawdust. Similarly, in our cut-tree experiment, the $F_{d}$ estimated from our sensors were significantly higher than those on rooted trees of the same characteristics. We consider that this difference is partially the result of the removal of the root systems, which reduces the resistance to water flow into the sapwood. This can additionally help explain the faster $F_{d}$ values observed in our study on the first days on the experiment. Vertessy et al. (1997) observed a similar pattern, i.e., higher $F_{d}$ in the first day of a cut-tree experiment, compared to consecutive days, which they also attributed to the removal of the root system. While vessel clogging or the formation of tyloses or callus tissue around the cut stems might account for some of the reduction over time, the main reduction in our cut-tree experiment was observed from the first to the second day, and some trees showed an increment in $F_{d}$ towards the end of the experiment. As observed in (Fig. 4-B), $F_{d}$ for did not show a significant reduction after the second day of our experiment, making clogging or formation of tyloses less likely (see Fig. 3:a,b). Additionally, the formation of tyloses is an unlikely explanation of such reduction under short periods of time, because tyloses takes weeks 
or months to form (Kitin et al. 2010; McElrone et al. 2010).

Performance of MHR under rapidly changing temperatures

As sap flow research becomes more prevalent in extreme environments (Chan and Bowling 2017), especially those where the sap is exposed to freeze/thaw cycles, understanding the role of freeze/thaw-driven sap flow and non-traditional water-loss pathways such as stem water loss or water loss from leafless branches becomes highly relevant. For example, Hölttä et al. (2018) studied sap pressurization in birch (Betula pendula Roth.), and discussed that HD sensors, while accurate within the growing season, might overestimate sap flow during the winter because of the various factors affecting the measuring principle of the method (i.e., the differences in temperature). This has also been highlighted by Chan and Bowling (2017) where they subjected HD sensors to conditions similar to those expected in very cold climates. In their laboratory experiments, sap flow stopped when the temperature of the stem was below the freezing point, which confirmed that HD sensors can estimate very low or zero flows, despite sudden changes in temperature. However, in both studies, the ability of the HD method to estimate $F_{d}$ from differences in temperature (an important characteristic of the method), becomes a strong limitation under the extreme temperature changes observed during winter, because the method requires a thermal equilibrium at night to properly estimate $F_{d}$. Additionally, the unidirectional measurement nature of this method places limitations on the study of freeze/ thaw-driven sap flow, which is often bidirectional, and often in opposite directions at different depths of the sapwood simultaneously, such as shown in Fig. 7. While not the goal of this study, we have observed in both field and laboratory experiments, that the direction of flow at a given sapwood depth results from the complex interaction between: (a) the source of the nucleation point during freezing, (b) the intensity, frequency and duration of the changes in temperature, and (c) the mass of the stem and the conducting tissue. When these factors interact in specific ways, different sections of the sapwood might be frozen at different times, resulting in flow in opposite directions. In our freeze/thaw experiment using both MHR and HR algorithms to estimate $F_{d}$, we observed that sections inside the sapwood $1.5 \mathrm{~cm}$ apart can, under specific conditions, have flows in opposite directions.
Under such conditions, a single measurement point, which is typical of the traditional HD method, might miss some relevant patterns that can help explain redistribution of sap for cavitation repair, or redistribution of non-structural carbohydrates during the winter months (Hartmann and Trumbore 2016; Hölttä et al. 2018; Quentin et al. 2015). While most of our $F_{d}$ estimates with both MHR and HR on A. saccharum were under the measurement range of $\mathrm{HR}$, other ongoing research studies on maple syrup production which some authors of this work are involved with, have shown $F_{d}$ higher than $55 \mathrm{~cm}^{3} \mathrm{~cm}^{-2} \mathrm{~h}^{-1}$ in living tapped trees, when trees are subjected to natural freeze/thaw cycles (Gutierrez Lopez et al. unpublished data).

Thermal diffusivity ( $\mathrm{D}, \mathrm{cm}^{2} \mathrm{~s}^{-1}$ ) in both green wood and water changes with temperature (Bonales et al. 2017; Steinhagen 1977; Vandegehuchte and Steppe 2012a) and the conditions under which ice crystals form also affect its thermal conductivity (Bonales et al. 2017). However, in most sap flow studies D is often kept constant, even when the sap temperature is below the freezing point, primarily due to the low flows expected at such temperatures. The review of changes inD with temperature and $\theta_{\mathrm{v}}$ provided by Steinhagen (1977), suggests that $F_{d}$ measured at low temperatures might be the result of changes in D. However, according to our results, once sapwood temperature in the A. saccharum trunks was lower than $-5^{\circ} \mathrm{C}$, both MHR and HR registered near zero $F_{d}$ values, so changes in D below $-5^{\circ} \mathrm{C}$ cannot have any effect on $F_{d}$ measurements. According to Bonales et al. (2017) and Steinhagen (1977), D changes significantly below $-5^{\circ} \mathrm{C}$, in both green wood and water, which is consistent with our observations. But in our case, there was a large peak before the phase change which has not been reported before (Fig. 8), coinciding with the peaks in $\rho c$ estimated right below $0^{\circ} \mathrm{C}$ (Fig. 8), which resulted in $\theta_{\mathrm{v}}$ well over $300 \%$. However, if the $F_{d}$ we measured as a result of freeze/thaw cycles is primarily influenced by changes in thermal properties, such influence should disappear if $\mathrm{D}$ and $\theta_{\mathrm{v}}$ are kept constant. This was also tested, and the measured $F_{d}$ during both freezing and thawing appeared, but the amount of noise immediately below $0^{\circ} \mathrm{C}$ was significantly reduced. Recently, we observed the same pattern in pine (Pinus sylvestris), spruce (Picea abies) and birch (Betula pendula) trees in an ongoing study on transpiration of boreal forests in Northern Sweden: on nearly all monitored 
trees, once sapwood temperature and sap was below $-5{ }^{\circ} \mathrm{C}$, no $F_{d}$ was measured with either MHR nor HR, even when sapwood temperature fluctuated between $-5{ }^{\circ} \mathrm{C}$ and $-13^{\circ} \mathrm{C}$ for several days (Gutierrez Lopez et al. 2021). Nonetheless, this opens new questions regarding how to best apply the known changes in D and $\rho c$ with temperature to sap flow measurements in places where transpiration occurs simultaneously with freeze/thaw cycles. If $\mathrm{D}$ is adjusted to changes in temperature below $0^{\circ} \mathrm{C}$, many flows will be significantly reduced because its main influence on $\mathrm{V}_{\mathrm{h}}$ in Eq. 10. However, solving Eq. 4 at zero flows, results in stable $\rho c$ until $0^{\circ} \mathrm{C}$, below that, there is a significant $\rho c$ increment during both freezing and thawing, which as previously mentioned, directly affects $\theta_{\mathrm{v}}$ in Eq. 15, and subsequently $F_{d}$ in Eq. 13 . Freeze/ thaw cycles do not only affect thermometric sap flow sensors. We have observed similar $\theta_{\mathrm{v}}$ changes with temperature fluctuations in similarly-sized Acer saccharum trunks that we subjected to deep $\left(-20^{\circ} \mathrm{C}\right.$ to $20^{\circ} \mathrm{C}$ ) freeze/thaw cycles where $\theta_{\mathrm{v}}$ was monitored using GS-3 capacitance sensors (METER Group, Pullman, WA. USA) (Gutierrez Lopez, unpublished data). While capacitance sensors have been calibrated and successfully used before to estimate $\theta_{\mathrm{v}}$ (Matheny et al. 2017), their reliability within freeze/thaw cycles remains to be tested, especially since we know that in some species, freeze/thaw cycles results in bidirectional sap flow. Finally, we have tested MHR with both Type-T thermocouples and with high-precision thermistors, and the only difference we have observed so far is the higher measurement stability of thermistors, as long as a first-level linearization circuit is implemented in the sensor design (Baker 2002). At this moment, we are not certain whether HD sensors can be reliably used to monitor $F_{d}$ during winter-time or freeze/thaw cycles, considering that the heated probe is maintained at approximately $40^{\circ} \mathrm{C}$, which we are certain results in a bubble of liquid sap around the heating element, potentially affecting $F_{d}$ measurements during critical times during the winter.

\section{Conclusions}

The alterative MHR method allowed us to significantly increase the measurement range of HR to $F_{d}$ values up to $130 \mathrm{~cm}^{3} \mathrm{~cm}^{-2} \mathrm{~h}^{-1}$, which is greater than the range reported for most tree species. In general, the $F_{d}$ estimates obtained from MHR and HR were well correlated within -45 to $45 \mathrm{~cm}^{3} \mathrm{~cm}^{-2} \mathrm{~h}^{-1}$ in the species we studied, but HR had a small overestimation memory effect only when $F_{d}$ was outside the measuring range of HR. The initial $\Delta \operatorname{Tmax}_{\mathrm{u}} / \Delta \mathrm{Tmax}_{\mathrm{d}}$ ratio showed also a strong relationship with actual gravimetric water use. In smaller stems with large LAI/A ratio, where $F_{d}$ tends to be very fast, MHR resulted in more stable estimates and less noise than HR; however, there was a high correlation between them, and when a smoothing function was applied to both, no significant differences were observed. In this study, which is based on field measurements and laboratory experiments, we show that MHR is a viable alternative that can be easily implemented in equidistantprobe HP sensor designs to monitor inverse, slow and fast flux densities. On Campbell Scientific (Campbell Scientific Inc.) data loggers, only minor variations to a CRBasic script are needed to run both MHR and HR simultaneously (so the user is not forced to pick one over the other), be processed online (using the data logger's memory) and stored as a single value per measurement with limited programing. Additionally, if no data memory restrictions exist, all raw data can be stored and both HR and MHR algorithms can be run for comparison purposes a posteriori, from where thermal properties and sapwood volumetric water content in the stem can be estimated. Because new/improved algorithms are constantly under development, we strongly advice to save raw data at no less than $1 \mathrm{~Hz}$ (although multiplexing speeds might make this difficult under some configurations). Finally, this algorithm can also be applied on previously collected raw data, if HR was unable to predict $F_{d}$ values higher than $60 \mathrm{~cm}^{3} \mathrm{~cm}^{-2} \mathrm{~h}^{-1}$. However, as a final conclusion, further research and experiments under controlled conditions on different species and wood anatomies are needed to understand how thermal diffusivity and thermal conductivity at low temperatures affect sap flow estimates.

Authors' contributions JGL performed the experiments, analyzed the data, wrote the first manuscript draft, and build upon the initial MHR algorithm to incorporate thermal properties and volumetric water content. TP, JL, and HA conceived the overarching project, helped with international collaborations, and provided help revising manuscript drafts. SB helped revising manuscript drafts, shared the initial idea of the MHR algorithm with the team. 
Funding Open access funding provided by Swedish University of Agricultural Sciences. This study was supported by an NSF OISE-PIRE project. Grant ID: 1243444.

Data availability Data available in the following repository: https://github.com/joseagl/MHR

Code availability CRBasic codes to run the MHR and HR algorithms are fully available in the following repository: https://github.com/joseagl/MHR

\section{Declarations}

Conflicts of interest/Competing interests Stephen Burgess receives royalties from HRM sensors marketed by ICT International Pty Ltd (not used in this study).

Open Access This article is licensed under a Creative Commons Attribution 4.0 International License, which permits use, sharing, adaptation, distribution and reproduction in any medium or format, as long as you give appropriate credit to the original author(s) and the source, provide a link to the Creative Commons licence, and indicate if changes were made. The images or other third party material in this article are included in the article's Creative Commons licence, unless indicated otherwise in a credit line to the material. If material is not included in the article's Creative Commons licence and your intended use is not permitted by statutory regulation or exceeds the permitted use, you will need to obtain permission directly from the copyright holder. To view a copy of this licence, visit http://creativecommons.org/licenses/by/4.0/.

\section{References}

Almeida AC, Soares JV, Landsberg JJ, Rezende GD (2007) Growth and water balance of Eucalyptus grandis hybrid plantations in Brazil during a rotation for pulp production. For Ecol Manag 251:10-21

Alsheimer M, Kostner B, Falge E, Tenhunen JD (1998) Temporal and spatial variation in transpiration of Norway spruce stands within a forested catchment of the Fichtelgebirge, Germany. Ann Des Sci Forestieres 55:103-123

Alvarado-Barrientos MS, Hernandez-Santana V, Asbjornsen H (2013) Variability of the radial profile of sap velocity in Pinus patula from contrasting stands within the seasonal cloud forest zone of Veracruz, Mexico. Agric For Meteorol 168:108-119

Baker BC (2002) Thermistors in single supply temperature sensing circuits. Page 12. Microchip Technology, Tempe, Arizona

Bates D, Mächler M, Bolker B, Walker S (2015) Fitting linear mixed-effects models using lme4. J Stat Softw 67:48

Becker P (1998) Limitations of a compensation heat pulse velocity system at low sap flow: implications for measurements at night and in shaded trees. Tree Physiol 18:177-184

Benyon RG (1999) Nighttime water use in an irrigated Eucalyptus grandis plantation. Tree Physiol 19:853-859
Berdanier AB, Miniat CF, Clark JS (2016) Predictive models for radial sap flux variation in coniferous, diffuseporous and ring-porous temperate trees. Tree Physiol 36:932-941

Bonales LJ, Rodriguez AC, Sanz PD (2017) Thermal conductivity of ice prepared under different conditions. Int J Food Properties 20:610-619

Burgess SSO, Adams M, Turner NC et al (2001) An improved heat pulse method to measure low and reverse rates of sap flow in woody plants (vol 21, pg 589, 2001). Tree Physiol 21:1157-1157

Burgess SSO, Adams MA, Bleby TM (2000) Measurement of sap flow in roots of woody plants: a commentary. Tree Physiol 20:909-913

Bush SE, Hultine KR, Sperry JS, Ehleringer JR (2010) Calibration of thermal dissipation sap flow probes for ringand diffuse-porous trees. Tree Physiol 30:1545-1554

Cabibel B, Do F (1991) Thermal measurements of sap flux in trunks and roots and hydrous behavior of trees. 1. Theoretical-analysis of the errors in sap-flux estimations and measurement validation in the presence of external thermal-gradients. Agronomie 11:669-678

Campbell GS, Calissendorff C, Williams JH (1991) Probe for measuring soil specific heat using a heat-pulse method. Soil Science Society of America Journal 55:291-293

Carslaw HS, Jaeger JC (1947) Conduction of heat in solids, 2nd edn. Oxford University Press, London

Caylor KK, Dragoni D (2009) Decoupling structural and environmental determinants of sap velocity: Part I. Methodol Dev Agric For Meteorol 149:559-569

Chan AM, Bowling DR (2017) Assessing the thermal dissipation sap flux density method for monitoring cold season water transport in seasonally snow-covered forests. Tree Physiol 37:984-995

Cienciala E, Kučera J, Lindroth A (1999) Long-term measurements of stand water uptake in Swedish boreal forest. Agric For Meteorol 98-99:547-554

Clearwater MJ, Meinzer FC, Andrade JL et al (1999) Potential errors in measurement of nonuniform sap flow using heat dissipation probes. Tree Physiol 19:681-687

Cleveland WS (1979) Robust locally weighted regression and smoothing scatterplots. J Amer Statist Assoc 74:829-836

Cleveland WS (1981) Lowess - a Program for Smoothing Scatterplots by Robust Locally Weighted Regression. Am Stat 35:54-54

Cody WJ, Thacher HC (1968) Rational Chebyshev approximations for the axponential integral $\mathrm{E}<\mathrm{sub}>1</$ sub $>$ (x). Math Comput 22:641-649

Cohen Y, Fuchs M, Green GC (1981) Improvement of the heat pulse method for determining sap flow in trees. Plant Cell Environ 4:391-397

Delzon S, Loustau D (2005) Age-related decline in stand water use: sap flow and transpiration in a pine forest chronosequence. Agric For Meteorol 129:105-119

Do F, Rocheteau A (2002) Influence of natural temperature gradients on measurements of xylem sap flow with thermal dissipation probes. 2. Advantages and calibration of a noncontinuous heating system. Tree Physiol 22:649-654

Dye PJ, Soko S, Poulter AG (1996) Evaluation of the heat pulse velocity method for measuring sap flow in Pinus patula. J Exp Bot 47:975-981 
Eller CB, Burgess SSO, Oliveira RS (2015) Environmental controls in the water use patterns of a tropical cloud forest tree species, Drimys brasiliensis (Winteraceae). Tree Physiol 35:387-399

Fernandez JE, Duran PJ, Palomo MJ et al (2006) Calibration of sap flow estimated by the compensation heat pulse method in olive, plum and orange trees: relationships with xylem anatomy. Tree Physiol 26:719-728

Flo V, Martinez-Vilalta J, Steppe K et al (2019) A synthesis of bias and uncertainty in sap flow methods. Agric For Meteorol 271:362-374

Forrester DI, Collopy JJ, Morris JD (2010) Transpiration along an age series of Eucalyptus globulus plantations in southeastern Australia. For Ecol Manag 259:1754-1760

Forster M (2017) How reliable are heat pulse velocity methods for estimating tree transpiration? Forests 8:350

Forster MA (2019) The Dual Method Approach (DMA) Resolves Measurement Range Limitations of Heat Pulse Velocity Sap Flow Sensors. Forests 10:46

Forster MA (2020) The importance of conduction versus convection in heat pulse sap flow methods. Tree Physiol 40:683-694

Goulet V (2016) expint: exponential integral and incomplete gamma function

Granier A (1985) Une nouvelle méthode pour la mesure du flux de sève brute dans le tronc des arbres. Ann For Sci 42:193-200

Granier A, Anfodillo T, Sabatti M et al (1994) Axial and Radial Water-Flow in the Trunks of Oak Trees - a Quantitative and Qualitative-Analysis. Tree Physiol 14:1383-1396

Gutierrez Lopez H, Asbjornsen J, Pypker T, Licata J (2018) Analysis of changes in the current supplied to heat dissipation sensors. Pages 155-160. International Society for Horticultural Science (ISHS), Leuven, Belgium

Gutierrez Lopez J, Tor-ngern P, Oren R et al (2021) How tree species, tree size, and topographical location influenced tree transpiration in northern boreal forests during the historic 2018 drought. Global Change Biology

Gutiérrez Lopez JA, Licata J, Pypker T, Asbjomsen H (2018) Analysis of changes in the current supplied to heat dissipation sensors using an improved tree-cut experiment on young Eucalyptus grandis trees. Tree Physiol

Hartmann H, Trumbore S (2016) Understanding the roles of nonstructural carbohydrates in forest trees - from what we can measure to what we want to know. New Phytol 211:386-403

Hasper TB, Wallin G, Lamba S et al (2016) Water use by Swedish boreal forests in a changing climate. Functional Ecology 30:690-699

Hogg EH, Hurdle PA (1997) Sap flow in trembling aspen: implications for stomatal responses to vapor pressure deficit. Tree Physiol 17:501-509

Hölttä T, Dominguez Carrasco MDR, Salmon Y et al (2018) Water relations in silver birch during springtime: how is sap pressurised? Plant Biol 20:834-847

Intrigliolo DS, Lakso AN, Piccioni RM (2009) Grapevine cv. "Riesling" water use in the northeastern United States. Irrigation Sci 27:253-262

Kagawa A, Sack L, Duarte K, James S (2009) Hawaiian native forest conserves water relative to timber plantation: Species and stand traits influence water use. Ecol Appl 19:1429-1443

Kallarackal J (2010) Water use by Eucalyptus grandis plantations in comparison with grasslands located in the downhill areas of Mannavan Shola in the Western Ghats of Kerala. Thrissur, Kerala, India

Kitin P, Voelker SL, Meinzer FC et al (2010) Tyloses and phenolic deposits in xylem vessels impede water transport in low-lignin transgenic poplars: a study by cryo-fluorescence microscopy. Plant Physiol 154:887-898

Kostner B, Falge E, Tenhunen JD (2002) Age-related effects on leaf area/sapwood area relationships, canopy transpiration and carbon gain of Norway spruce stands (Picea abies) in the Fichtelgebirge, Germany. Tree Physiol 22:567-574

Kozii N, Haahti K, Tor-ngern P et al (2020) Partitioning growing season water balance within a forested boreal catchment using sap flux, eddy covariance, and a process-based model. Hydrol Earth Syst Sci 24:2999-3014

Kukowski KR, Schwinning S, Schwartz BF (2013) Hydraulic responses to extreme drought conditions in three co-dominant tree species in shallow soil over bedrock. Oecologia 171:819-830

Lagergren F, Lindroth A (2002) Transpiration response to soil moisture in pine and spruce trees in Sweden. Agric For Meteorol 112:67-85

Lever J, Krzywinski M, Altman N (2016) Model selection and overfitting. Nat Methods 13:703-704

Lu P, Chacko E (1998) Evaluation of Granier's sap flux sensor in young mango trees. Agronomie 18:461-471

Lundblad M, Lagergren F, Lindroth A (2001) Evaluation of heat balance and heat dissipation methods for sapflow measurements in pine and spruce. Ann for Sci 58:625-638

Lundblad M, Lindroth A (2002) Stand transpiration and sapflow density in relation to weather, soil moisture and stand characteristics. Basic and Applied Ecology 3:229-243

Marshall DC (1958) Measurement of Sap Flow in Conifers by Heat Transport. Plant Physiol 33:385-396

Matheny AM, Garrity SR, Bohrer G (2017) The Calibration and Use of Capacitance Sensors to Monitor Stem Water Content in Trees. J Vis Exp 57062

McElrone AJ, Grant JA, Kluepfel DA (2010) The role of tyloses in crown hydraulic failure of mature walnut trees afflicted by apoplexy disorder. Tree Physiol 30:761-772

Meinzer FC, James SA, Goldstein G (2004) Dynamics of transpiration, sap flow and use of stored water in tropical forest canopy trees. Tree Physiol 24:901-909

Oishi AC, Hawthorne DA, Oren R (2016) Baseliner: An opensource, interactive tool for processing sap flux data from thermal dissipation probes. SoftwareX 5:139-143

Peters RL, Fonti P, Frank DC et al (2018) Quantification of uncertainties in conifer sap flow measured with the thermal dissipation method. New Phytol 219:1283-1299

Poblete-Echeverria C, Ortega-Farias S, Zuniga M, Fuentes S (2012) Evaluation of compensated heat-pulse velocity method to determine vine transpiration using combined measurements of eddy covariance system and microlysimeters. Agric Water Manag 109:11-19

Quentin AG, Pinkard EA, Ryan MG et al (2015) Non-structural carbohydrates in woody plants compared among laboratories. Tree Physiol 35:1146-1165 
Rabbel I, Diekkruger B, Voigt H, Neuwirth B (2016) Comparing Delta T-max Determination Approaches for GranierBased Sapflow Estimations. Sensors 16

Regalado CM, Ritter A (2007) An alternative method to estimate zero flow temperature differences for Granier's thermal dissipation technique. Tree Physiol 27:1093-1102

Schreel JDM, Steppe K (2019) Foliar water uptake changes the world of tree hydraulics. npj Clim Atmos Sci 2:1

Steinhagen PH (1977) Thermal properties of wood, green or dry from -40 to $+100 \mathrm{C}$ : a literature review. FPL -9 , USDA Forest Service, Madison, Wisconsin

Steppe K, De Pauw DJW, Doody TM, Teskey RO (2010) A comparison of sap flux density using thermal dissipation, heat pulse velocity and heat field deformation methods. Agric For Meteorol 150:1046-1056

Steppe K, De Pauw DJW, Lemeur R, Vanrolleghem PA (2006) A mathematical model linking tree sap flow dynamics to daily stem diameter fluctuations and radial stem growth. Tree Physiol 26:257-273

Sun HZ, Aubrey DP, Teskey RO (2012) A simple calibration improved the accuracy of the thermal dissipation technique for sap flow measurements in juvenile trees of six species. Trees-Struct Funct 26:631-640

Swanson RH (1962) An instrument for detecting sap movement in woody plants. 68 , Fort Collins, Colorado, USA

Swanson RH (1994) Significant historical developments in thermal methods for measuring sap flow in trees. Agric For Meteorol 72:113-132

Vandegehuchte MW, Burgess SSO, Downey A, Steppe K (2015) Influence of stem temperature changes on heat pulse sap flux density measurements. Tree Physiol $35: 346-353$
Vandegehuchte MW, Steppe K (2012a) Improving sap flux density measurements by correctly determining thermal diffusivity, differentiating between bound and unbound water. Tree Physiol 32:930-942

Vandegehuchte MW, Steppe K (2012b) Sapflow+: a four-needle heat-pulse sap flow sensor enabling nonempirical sap flux density and water content measurements. New Phytol 196:306-317

Vandegehuchte MW, Steppe K (2013) Sap-flux density measurement methods: working principles and applicability. Functional Plant Biology 40:213-223

Vergeynst LL, Vandegehuchte MW, McGuire MA et al (2014) Changes in stem water content influence sap flux density measurements with thermal dissipation probes. TreesStruct Funct 28:949-955

Vertessy RA, Hatton TJ, Reece P et al (1997) Estimating stand water use of large mountain ash trees and validation of the sap flow measurement technique. Tree Physiol 17:747-756

Wullschleger SD, King AW (2000) Radial variation in sap velocity as a function of stem diameter and sapwood thickness in yellow-poplar trees. Tree Physiol 20:511-518

Zalesny RS, Wiese AH, Bauer EO, Riemenschneider DE (2006) Sapflow of hybrid poplar (Populus nigra L. X P-maximowiczii A. Henry 'NM6') during phytoremediation of landfill leachate. Biomass Bioenergy 30:784-793

Publisher's note Springer Nature remains neutral with regard to jurisdictional claims in published maps and institutional affiliations. 